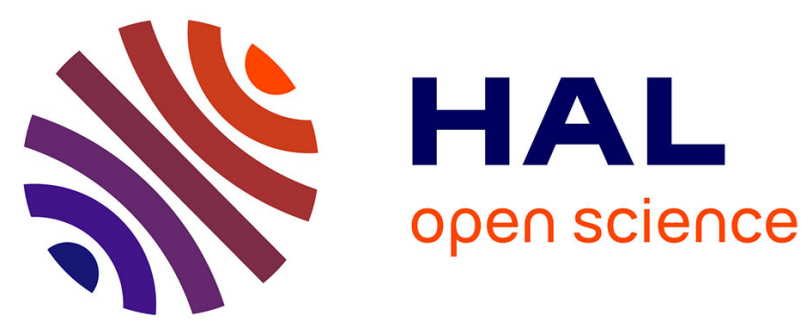

\title{
Contracts as a Barrier to Entry: Impact of Buyer's Asymmetric Information and Bargaining Power
}

\author{
David Martimort, Jérôme Pouyet, Thomas Trégouët
}

\section{To cite this version:}

David Martimort, Jérôme Pouyet, Thomas Trégouët. Contracts as a Barrier to Entry: Impact of Buyer's Asymmetric Information and Bargaining Power. International Journal of Industrial Organization, 2021, 79, pp.102791. 10.1016/j.ijindorg.2021.102791 . hal-03328387v2

\section{HAL Id: hal-03328387 \\ https://hal.science/hal-03328387v2}

Submitted on 16 Dec 2021

HAL is a multi-disciplinary open access archive for the deposit and dissemination of scientific research documents, whether they are published or not. The documents may come from teaching and research institutions in France or abroad, or from public or private research centers.
L'archive ouverte pluridisciplinaire HAL, est destinée au dépôt et à la diffusion de documents scientifiques de niveau recherche, publiés ou non, émanant des établissements d'enseignement et de recherche français ou étrangers, des laboratoires publics ou privés. 


\title{
Contracts as a Barrier to Entry: Impact of Buyer's Asymmetric Information and Bargaining Power*
}

\author{
David MartimorT ${ }^{\dagger}$ JÉrôme Pouyet ${ }^{\ddagger}$ Thomas TrégouëT ${ }^{\S}$
}

November 8, 2021

\begin{abstract}
An incumbent seller contracts with a buyer under the threat of entry. The contract stipulates a price and a penalty for breach if the buyer later switches to the entrant. Sellers are heterogenous in terms of the gross surplus they provide to the buyer. The buyer is privately informed on her valuation for the incumbent's service. Asymmetric information makes the incumbent favor entry as it helps screening buyers. When the entrant has some bargaining power vis-à-vis the buyer and keeps a share of the gains from entry, the incumbent instead wants to reduce entry. The compounding effect of these two forces may lead to either excessive entry or foreclosure, and possibly to a fixed rebate for exclusivity which is afforded to all buyers.
\end{abstract}

KEYwORDS: Foreclosure; excessive entry; exclusionary behavior; incomplete information.

JEL CODE: L12, D82.

\section{INTRODUCTION}

Motivation. Exclusive clauses are prevalent in platform markets. In its recent antimonopoly guidelines for platform economy, China's competition regulator especially targeted exclusive agreements, such as the so called "choose one between two" clause under which a platform prevents a merchant from selling on multiple platforms. ${ }^{1}$ As of 2018 ,

${ }^{*}$ We thank people at Altermind for stimulating discussions at the inception of this project. We also thank two referees and the Editor, Giacomo Calzolari, for important remarks that helped us significantly revise this project. The first author also thanks Toulouse School of Economics for its hospitality and for financial support from the ERC (MARKLIN). All remaining errors are ours.

${ }^{\dagger}$ Paris School of Economics (EHESS). E-mail: david.martimort@psemail.eu. Address: PSE, 48 boulevard Jourdan, 75014 Paris, France.

${ }^{\ddagger}$ CY Cergy Paris Université, CNRS, THEMA and ESSEC Business School. E-mail: pouyet@essec.edu. Address: ESSEC Business School, Avenue Bernard Hirsch, BP 50105, 95021 Cergy, France.

${ }^{\S}$ CY Cergy Paris Université, CNRS, THEMA. E-mail: thomas.tregouet@u-cergy.fr. Address: THEMA, Université de Cergy-Pontoise, 33 Boulevard du Port, 95011 Cergy Pontoise Cedex, France.

${ }^{1}$ On 7 February 2021, the Antimonopoly Committee of the State Council issued the Antimonopoly Guidelines on Platform Economic Sector, which is China's first specific antitrust rules on platforms (see http://gkml.samr.gov.cn/nsjg/fldj/201904/t20190429_293282.html). 
the Indian regulator banned exclusive contracts between platforms and merchants. ${ }^{2}$ In 2019, the EU Commission concluded that "Google first imposed an exclusive supply obligation, which prevented competitors from placing any search adverts on the commercially most significant websites. Then, Google introduced what it called its "relaxed exclusivity" strategy aimed at reserving for its own search adverts the most valuable positions and at controlling competing adverts' performance." ${ }^{3}$ Last, an investigation launched by the French Competition Authority unveiled that brands were tied in various ways to the dominant operator in the flash-sales market. ${ }^{4}$ These examples all point in the same direction: Exclusivity provisions are practices that are widely spread in the digital economy.

In this article, we revisit the rationale for exclusivity clauses in a context, particularly relevant for the digital economy, where a dominant firm deals with a large number of heterogenous buyers and faces the threat of entry by a competing seller. We shall argue that exclusivity provisions have then a screening purpose that tends to alleviate their foreclosure effect.

Model AND Results. Our model is directly inspired from Aghion and Bolton (1987)'s seminal work on contracts as a barrier to entry. We adapt their framework to economic contexts that prevail in the digital economy. An incumbent firm (or platform) provides one unit of service (or digital service) to a buyer (a merchant) but faces the threat of entry by a rival who might be more attractive. The incumbent firm can commit ex ante to a contract with the buyer. This contract stipulates a price for the seller's service as well as a penalty for breach (or early termination fee) if the buyer decides to switch later on to the entrant. The difference between the price and the penalty will often be referred to as a rebate for exclusivity. The penalty for breach acts as a rent-shifting tool for the seller to appropriate the potential gains of entry.

In Aghion and Bolton (1987), the incumbent and the entrant differ in their costs of providing the service and the buyer's valuation for this service is common knowledge. We depart from this framework in some important ways. First, the incumbent and the entrant no longer differ in terms of their costs of providing the service but with respect to the buyer's value of the service that those sellers may generate. In the digital economy, (marginal) costs can be considered as being null and platform sellers are differentiated in terms of the various pools of customers that they give access to their merchants. Second, the buyer might be privately informed on her valuation for the incumbent's service. An alternative interpretation is that there is a continuum of heterogeneous buyers who differ in terms of their valuations for that service. Again, this assumption appears quite realistic in the case of large dominant platforms which remain by and large ignorant of merchants' market opportunities.

In this context, our first contribution is to analyze the impact of asymmetric informa-

\footnotetext{
2 "E-commerce marketplace entity will not mandate any seller to sell any product exclusively on its platform only," Ministry of Commerce \& Industry, Press Note No.2 (2018), available at https://dipp.gov.in/sites/default/files/pn2_2018_0.pdf.

${ }^{3} \mathrm{See} \quad$ https://ec.europa.eu/ireland/news/commission-fines-google-1.49-billion-euro-for-abusivepractices-in-online-advertising_en.

${ }^{4}$ See Decision 14-D-18 of $28^{\text {th }}$ November 2014 (https://www.autoritedelaconcurrence.fr/fr/decision/relativedes-pratiques-mises-en-oeuvre-dans-le-secteur-de-la-vente-evenementielle-en-ligne). Although the complaint was dismissed, the main reason being that the relevant market had not been properly defined, the decision suggests that exclusivity clauses had anti-competitive effects. Exclusivity clauses concerned the duration of the exclusivity (which exceeded by far the duration of a flash-sale) and also the scope (i.e., different products of a given brand).
} 
tion on the capability of the incumbent seller to erect barrier to entry through contract design, stressing the role that exclusivity provisions may serve. To isolate this impact from other forces, we first assume that the buyer has all the bargaining power in her relationship with the entrant; an assumption that is later relaxed. In that polar scenario, the buyer can reap all gains from entry if she buys from the entrant. If, additionally, there is complete information between the incumbent and the buyer, there are no reasons for the incumbent to distort inefficiently entry since the incumbent-buyer coalition appropriates all the entry gains. The rebate for exclusivity is thus zero and there is neither inefficient foreclosure nor inefficient entry. Those entry gains end up being pocketed by the incumbent through an adequate choice of the penalty for breach.

This efficiency result no longer holds when the incumbent is uninformed about the buyer's valuation for its service, since in this scenario, he can no longer tailor the penalty for breach to the foregone surplus. Under asymmetric information, screening the different types of buyers now becomes an issue. In our context, and even if buyers have unit demand, screening remains feasible because buyers with higher valuations for the incumbent's service have less incentives to switch to the entrant. Therefore, the probability of letting entry occur can be used as a screening device by playing on the penalty for breach. Under asymmetric information, some information rent must be left to buyers to induce information revelation on surplus. To limit those rents, the incumbent increases the rebate above its full information level. So doing discourages buyers from underreporting their valuation, for this would imply to forego large gains from trade with the incumbent. Increasing the rebate also means decreasing the penalty for breach relative to the price for the incumbent's service; which facilitates entry. Therefore, asymmetric information makes the incumbent softer vis-à-vis the entrant and leads to socially excessive entry.

Our second contribution is to study the role of the buyer's bargaining power vis-à-vis the entrant. When the buyer does not capture all the gains associated to entry and leave the entrant with some share of those, the incumbent is willing to inefficiently distort entry so as to reduce the share of the rent that cannot be ultimately pocketed back. ${ }^{5}$ The incumbent should now set a negative rebate for exclusivity; which has a foreclosure effect on the entrant. This result revisits in our specific context the so called rent-shifting effect, as highlighted first by Aghion and Bolton (1987).

While asymmetric information calls for positive rebates for exclusivity as seen above, the fact that the buyer might not have all the bargaining power vis-à-vis the entrant instead requires to set negative rebates. There is thus a significant tension between the two polar objectives of the contract, namely extracting information rent from the buyer and extracting bargaining rent from the entrant. When both asymmetric information and limited bargaining power on the buyer's side are present altogether, the optimal rebate trades off these two effects. The tension between those two objectives can be so strong that the optimal incentive compatible contract entails a fixed rebate and all buyers, whatever their types, are bunched on the same inflexible allocation.

Literature REVIEW. Our article belongs to the literature that analyzes the strategic role of contracts in market contexts. The so called Chicago School of Antitrust (Posner, 1976; Bork, 1978) defended the view that an upstream incumbent seller does not want to lock down its buyer in an exclusive relationship that inefficiently deters the entry of

\footnotetext{
${ }^{5}$ Because the incumbent-buyer coalition no longer reaps all the gains from entry, the incumbent now wants to reduce entry.
} 
a more efficient competitor. In an influential article, Aghion and Bolton (1987) showed that contracts can erect entry barrier when there is uncertainty on the efficiency gains of entry and when the incumbent cannot fully appropriate these gains. With respect to their analysis, we keep the assumption that the buyer has a unit demand but add two key ingredients. First, sellers differ not in the cost of supplying the buyer but in the surpluses they provide to the buyer. Second, there is asymmetric information about the buyer's valuation for the incumbent's service. Rebates for exclusivity have thus a screening purpose.

Several analyses have extended Aghion and Bolton (1987)'s framework towards various directions. Marx and Shaffer $(1999,2004)$ consider a multi-unit demand buyer and analyze how contractual restrictions may limit the incumbent seller's ability to shift back the rent from entry. Choné and Linnemer $(2015,2016)$ and Martimort, Pouyet and Stole (2017) further add asymmetric information (on the buyer's preferences and on the entry cost) and the possibility that the incumbent seller is a dominant firm (in the sense that it is an essential trading partner for a fraction of the buyer's demand). These articles study the exclusionary properties of nonlinear price-quantity schedules, depending on whether the price charged by the dominant firm depends on the quantity purchased from the rival firm or not. Ide, Montero and Figueroa (2016) examine how the surplus between the dominant seller and the buyer is shared when ex ante lump-sum transfers are ruled out. They show that some ex ante commitment is required to generate inefficient foreclosure and is thus subject to a possibility of renegotiation or, conversely, that in the absence of commitment, exclusion becomes impossible. Our model endows the incubent with such an ex ante commitment power.

Still considering asymmetric information about the buyer's preferences, Calzolari and Denicolò (2013) investigate market-share discounts and exclusive contracts in a symmetric duopoly setting with multi-unit demand. Calzolari and Denicolò (2015) relax the symmetry assumption by assuming that one firm has a competitive advantage (either on cost or on quality) over its rivals and is thus dominant. In these papers, exclusivity plays the role of a screening device whose effects come in addition to standard screening distortions in a multi-unit demand context. Our model differs from Calzolari and Denicolò (2015) on several grounds. First, the buyer has limited bargaining power over the entrant. Second, the buyer's valuations for the incumbent's and the entrant's services are independent random variables. Third, only one unit is traded with precludes the use of quantity as a screening device. Yet, exclusivity plays also a key role as a screening tool in our context as well. However, we somehow confirm their earlier result that inefficient foreclosure or socially excessive entry may both arise in equilibrium depending on the sharing of the bargaining power between the buyer and the entrant.

Finally, another strand of the literature, less related to our contribution, investigates how mis-coordination among several independent buyers (Rasmusen, Ramseyer and Wiley, 1991; Innes and Sexton, 1994; Segal and Whinston, 2000; Spector, 2011; Chen and Shaffer, 2014 and 2019; Bedre-Defolie and Biglaiser, 2017) or the presence of several competing buyers (Fumagalli and Motta, 2006; Simpson and Wickelgren, 2007; Abito and Wright, 2008; Asker and Bar-Isaac, 2014; Wright, 2009) might also facilitate vertical foreclosure.

Organization of the PAPER. Section 2 presents the model and analyzes a benchmark where no contract is ever signed. Section 3 considers the symmetric information scenario with contract signing and shows that entry is socially efficient when the buyer has all 
bargaining power vis-à-vis the entrant. Section 4 shows that asymmetric information between the incumbent and the buyer leads to an excessive level of entry. Section 5 studies the situation in which the entrant has some bargaining power vis-à-vis the buyer. There, we show that, first, entry may instead be restricted and second, that inflexible contracts can emerge as a response to the conflicting objectives of extracting information rent from the buyer and bargaining rent from the entrant. All proofs are relegated to an Appendix.

\section{Model AND BenChMARK}

MARKET STRUCTURE AND INFORMATION. We consider how the relationship between an incumbent seller $I$ (he) and his buyer $B$ (she) may be disrupted by the entry of a competing seller $E$. $I$ provides a service to $B$. To illustrate, $I$ might be a well-established platform that attracts a traditional clientele. The buyer's valuation for $I$ 's service is denoted by $v_{1}$ and is distributed according to a common knowledge distribution $G_{1}$, with (strictly positive) density $g_{1}=G_{1}^{\prime}$ on a support $[0, \bar{v}](\bar{v}>0)$. We assume that the monotone hazard rate property is satisfied, i.e., $\left(1-G_{1}\right) / g_{1}$ is decreasing. ${ }^{6}$ We normalize I's cost of providing the service to 0 .

A competing seller, referred to in the sequel as the entrant $E$, may enter the market and supply the buyer. For instance, a new platform may provide the merchant with access to a brand new and maybe more specialized clientele. The buyer's valuation for $E$ 's service is denoted by $v_{2}$ and is distributed according to a common knowledge distribution $G_{2}$, with (strictly positive) density $g_{2}=G_{2}^{\prime}$ on $[0, \bar{v}]$. To keep elements of the model as symmetric as possible between $I$ and $E$, we also assume that $\left(1-G_{2}\right) / g_{2}$ is decreasing and that $E$ 's cost of providing the service is also 0 . Beside, there are no fixed costs of entry.

Entry is socially efficient when $E$ supplies $B$ if and only if $v_{2} \geq v_{1}$, and $I$ supplies $B$ otherwise. In the sequel, we focus on whether there is either inefficient foreclosure or excessive entry.

Two situations are relevant for our analysis, depending on whether the incumbent relies on contracts or not when dealing with the buyer.

In the first scenario, referred to as the 'spot market scenario,' there is no contract signing. The timing then goes as follows:

0 . $B$ privately learns her valuation $v_{1}$ for $I$ 's service.

1. $I$ offers to supply the service at price $p_{1}$. $B$ may accept or reject that option to buy.

2. $B$ 's valuation for $E$ 's service, $v_{2}$, is realized and is learned by both $E$ and $B$.

3. A price $p_{E}$ is set for $E$ 's service. $B$ chooses whether to buy from $I$ or from $E$ and pays the corresponding price.

In this spot market scenario, $I$ and $E$ compete in prices to supply $B$, but $I$ has a firstmover advantage over $E$. Importantly, the price $p_{1}$ proposed by $I$ does not prevent $B$ from switching to $E$ at no extra cost if, once aware of her valuation for $E$ 's service, she

\footnotetext{
${ }^{6}$ Bagnoli and Bergstrom (2005).
} 
finds it more attractive to do so. In other words, in the spot market scenario, $I$ has no commitment power to force $B$ to purchase his own service even when moving first.

In the second scenario, $I$ and $B$ have signed a contract upfront. At date $1, I$ can also impose a penalty $p_{2}$ to $B$ if the buyer decides to switch to the entrant. Otherwise, the timing of events is unchanged.

Henceforth, $I$ keeps a first-mover advantage over $E$ in both scenarios. Contracts are not the source of $I$ 's first-mover advantage. Similarly, since $I$ remains uninformed about $B$ 's valuation in the spot market scenario, the information structure is also unchanged across scenarios. ${ }^{7}$ In other words, the sole difference between the scenario with contracts and the spot market comes from the impossibility for $I$ to punish switching decisions by means of a penalty for breach. ${ }^{8}$

The choice of a price $p_{E}$ at stage 3 of the game depends on how $B$ and $E$ negotiate. We follow Choné and Linnemer $(2015,2016)$ and Martimort, Pouyet and Stole (2017) in assuming that any trade between $B$ and $E$ takes place under complete information. This assumption is justified when the entrant is a more specialized platform that is better able to assess the merchants' needs.

Furthermore, and unless otherwise specified, we shall assume that $B$ has all the bargaining power in her relationship with $E$. This simplifying assumption, which shall be relaxed in Section 5, eases presentation. As detailed later on, it allows us to analyze how asymmetric information impacts entry absent any other distortionary motives. Notice that, since $B$ has all the bargaining power vis-à-vis $E, B$ can always command a price for $E$ 's service equal to $E$ 's marginal cost, i.e., $p_{E}=0$. Put differently, when $B$ has all bargaining power, everything happens as if the entrant were a competitive fringe with zero marginal cost.

Spot MARKet. At the last stage of the spot market game, given a price $p_{1}$ set by $I, B$ buys from $E$ when it is efficient to do so, i.e., when $v_{2} \geq v_{1}-p_{1}$, and from $I$ otherwise. Observe that the switching decision depends both on the surpluses delivered by the suppliers to the buyer (i.e., $v_{1}$ and $v_{2}$ ) and on the prices (i.e., $p_{1}$ and $p_{E}=0$ ).

$B$ 's expected benefit from accepting $I$ 's price at stage 1 of the game is thus given by

$$
\left(v_{1}-p_{1}\right) G_{2}\left(v_{1}-p_{1}\right)+\int_{v_{2} \geq v_{1}-p_{1}} v_{2} d G_{2}\left(v_{2}\right) .
$$

$B$ always has the option to reject I's price and to buy directly from $E$. This yields an expected gain for the buyer worth

$$
\int v_{2} d G_{2}\left(v_{2}\right)
$$

The following lemma compares $B$ 's expected gain depending on her decision to accept or to turn down I's price.

\footnotetext{
${ }^{7}$ It is worth stressing that, in Aghion and Bolton (1987)'s seminal study, firms compete head-to-head under complete information (about the entrant's cost) on the spot market. Therefore, when comparing the situations with and without contracts, both the timing and the information structure change. Our model does not have this flaw.

${ }^{8} \mathrm{~A}$ possible alternative interpretation is that the spot market scenario also describes settings where contracts are feasible but cannot be conditioned on purchases from competitors.
} 
Lemma 1. In the spot market, $B$ accepts I's price $p_{1}$ if and only if $v_{1} \geq p_{1}$.

When her valuation $v_{1}$ is smaller than $I$ 's price $p_{1}$, there is no point for $B$ to accept $I$ 's option to buy. When $v_{1}$ is instead greater, $B$ prefers accepting $I$ 's price, which gives the opportunity to buy later on, once her valuation $v_{2}$ is realized, from the supplier that provides the highest net surplus.

To characterize the spot market outcome, it remains to determine the price set by the incumbent. I's expected profit is equal to

$$
\Pi_{I}^{s m}\left(p_{1}\right)=\int_{v_{1} \geq p_{1}} p_{1} G_{2}\left(v_{1}-p_{1}\right) d G_{1}\left(v_{1}\right)
$$

where the superscript 'sm' stands for 'spot market.' When $v_{1} \leq p_{1}, B$ rejects $I$ 's price and buys directly from $E$. When $v_{1} \geq p_{1}, B$ accepts $I$ 's price but buys from $I$ only when switching to $E$ is not attractive.

The optimal price $p_{1}^{s m}$ maximizes the incumbent seller's profit $\Pi_{I}^{s m}\left(p_{1}\right)$. It is characterized by the following first-order condition ${ }^{9}$

$$
p_{1}^{s m}=\frac{\int_{v_{1} \geq p_{1}^{s m}} G_{2}\left(v_{1}-p_{1}^{s m}\right) d G_{1}\left(v_{1}\right)}{\int_{v_{1} \geq p_{1}^{s m}} g_{2}\left(v_{1}-p_{1}^{s m}\right) d G_{1}\left(v_{1}\right)} .
$$

In the spot market scenario, the price set by the incumbent trades off the following effects. A high price charged to the buyer tends to increase profit. However, such a high price also leads a buyer with a low valuation $v_{1}$ for $I$ 's service to buy directly from the entrant and makes switching to $E$ more attractive when the valuation $v_{2}$ for the entrant's service will be known.

For further reference, it is also useful to compute the buyer's expected gain in the spot market outcome. To do so, remind from Lemma 1 that a buyer with valuation $v_{1} \leq p_{1}^{s m}$ rejects $I$ 's offer, whereas a buyer with valuation $v_{1} \geq p_{1}^{s m}$ accepts that offer but sometimes buys from $E$ depending on the realization of her valuation $v_{2}$. Hence, $B$ 's expected rent writes as follows

$$
U_{B}^{s m}\left(v_{1}\right)=\max \left\{\left(v_{1}-p_{1}^{s m}\right) G_{2}\left(v_{1}-p_{1}^{s m}\right)+\int_{v_{2} \geq p_{1}^{s m}} v_{2} d G_{2}\left(v_{2}\right) ; \int v_{2} d G_{2}\left(v_{2}\right)\right\}
$$

Figure 1 summarizes the key features of the spot market benchmark. ${ }^{10}$ It illustrates an interesting finding: The spot market outcome is socially inefficient when $v_{1} \geq v_{2} \geq$ $v_{1}-p_{1}^{s m}$, for $B$ buys from the entrant rather than from the incumbent. In the next sections, we will analyze whether contracts worsen or improve on this scenario.

\section{Contracts under Symmetric Information}

From now on, $I$ has the possibility to offer a contract to $B$ at stage 1 of our game. A contract consists in, first a price $p_{1}$ if $B$ buys from $I$, and second, a penalty for breach

\footnotetext{
${ }^{9}$ This condition is also sufficient since the maximand is quasi-concave in $p_{1}$ given monotonicity of the hazard rate.

${ }^{10}$ Straightforward computations show that the first expression in the right-hand side of (2.2) is strictly increasing and strictly convex for $v_{1}>p_{1}^{s m}$ and has a slope equal to zero at $v_{1}=p_{1}^{s m}$.
} 


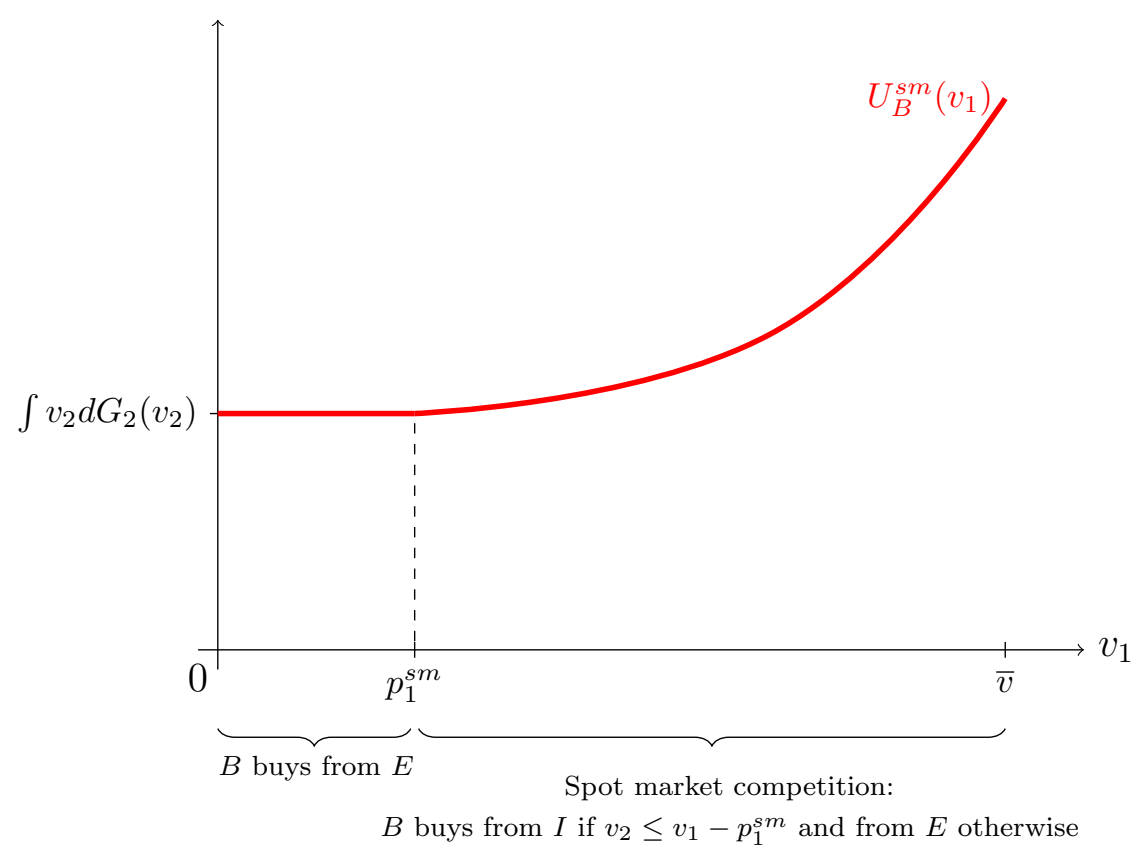

Figure 1: B's expected rent in the spot market outcome.

$p_{2}$ paid by $B$ if she switches to $E$. The buyer's switching decision depends now on the penalty for breach that $B$ has to pay when dealing with $E$, that is, $B$ switches to $E$ if and only if $v_{2}-p_{2} \geq v_{1}-p_{1}$. Depending both on valuations and prices, $B$ may thus be more or less inclined to switch to $E$ rather than to stay with $I$. This stands in contrast with Aghion and Bolton (1987). In their analysis, suppliers offer the same gross surplus $v$ to $B$ and differ in their unit cost. Hence, the buyer's decision to switch is independent on her valuation for the suppliers' services. Screening the different types of buyer through the penalty for breach thus becomes possible in our setting, even if the buyer has a unit demand for the suppliers' services.

Let $\Delta=p_{1}-p_{2}$. This variable can a priori be either positive or negative. When $p_{1} \leq p_{2}$, or $\Delta \leq 0$, the incumbent erects a barrier to entry by making the buyer's decision to switch to the entrant quite costly; $\Delta$ could then be viewed as a rebate for exclusivity offered by $I$ to $B$. Instead, when $p_{1} \geq p_{2}$, or $\Delta \geq 0, I$ facilitates entry. In the sequel, we shall often refer to $\Delta$ as a 'rebate for exclusivity,' keeping in mind that when $\Delta \geq 0, I$ wants to encourage $B$ to switch to $E$. Last, notice that if the optimal contract is such that $p_{2}=0$, the outcome actually coincides with that in the spot market scenario; therefore, any reference to a rebate $\Delta$ implicitly refers to a situation where $I$ finds it preferable to use a contract rather than to rely on the spot market.

The timing of events remains identical to that in the spot market benchmark, up to the fact that $I$ offers now a contract $\left(p_{1}, p_{2}\right)$ at the first stage of the game (or alternatively a pair $\left.\left(p_{1}, \Delta\right)\right)$. At stage $3, B$ switches to $E$ when $v_{2}-p_{2} \geq v_{1}-p_{1}$, or equivalently when $v_{2} \geq v_{1}-\Delta$. If $B$ rejects $I$ 's contract, then the game proceeds as in the spot market described in the previous section.

Since we keep the same timing of events in both sub-games (with spot market competition and with contract), the possibility to offer a contract does not empower $I$ with any ad hoc first-mover advantage over $E$. Therefore, our assumption allows us to clearly 
delineate how the additional price instrument provided by a contract can be used by the incumbent to change the competitive interaction with the entrant.

We analyze in this section the symmetric information benchmark, in which the buyer's valuation $v_{1}$ for the incumbent's service is known to $I$ at the time of contracting. Accordingly the contract can be conditioned on $v_{1}$ and we thus denote by $\left(p_{1}\left(v_{1}\right), \Delta\left(v_{1}\right)\right)$ such a contract. I's problem is thus to find the contract that maximizes his profit subject to the constraint that the buyer prefers accepting this contract rather than relying on the spot market for her supply.

When the buyer accepts the contract, she purchases from $I$ provided that $v_{2} \leq v_{1}-$ $\Delta\left(v_{1}\right)$, and then gets a surplus $v_{1}-p_{1}\left(v_{1}\right)$. She switches to $E$ when $v_{2} \geq v_{1}-\Delta\left(v_{1}\right)$, which yields a surplus $v_{2}-p_{2}\left(v_{1}\right)$. Hence, $B$ 's expected surplus may be rewritten as ${ }^{11}$

$$
U_{B}\left(v_{1}\right)=v_{1}-p_{1}\left(v_{1}\right)+\int_{v_{2} \geq v_{1}-\Delta\left(v_{1}\right)}\left(1-G_{2}\left(v_{2}\right)\right) d v_{2} .
$$

Therefore, for the buyer to accept the contract, it must be that

$$
U_{B}\left(v_{1}\right) \geq U_{B}^{s m}\left(v_{1}\right)
$$

where $U_{B}^{s m}\left(v_{1}\right)$ is defined by $(2.2)$.

When the buyer accepts the contract, the incumbent earns $p_{1}\left(v_{1}\right)$ when $B$ stays and $p_{2}\left(v_{1}\right)$ when $B$ switches to $E$. Hence, I's expected profit may be rewritten as follows

$$
\Pi_{I}\left(v_{1}\right)=p_{1}\left(v_{1}\right)-\Delta\left(v_{1}\right)\left(1-G_{2}\left(v_{1}-\Delta\left(v_{1}\right)\right)\right) .
$$

Next proposition describes the main properties of the optimal contract under symmetric information.

Proposition 1. Under symmetric information, I offers a contract with no rebate for exclusivity, i.e., $\Delta^{*}\left(v_{1}\right)=0$.

$I$ finds it worth offering a contract to $B$ but that contract stipulates no rebate for exclusivity. Intuitively, since $B$ has all the bargaining power vis-à-vis $E$, all gains from trade associated to switching to the entrant are captured by the buyer. Therefore, from the perspective of the incumbent-buyer coalition, which acts under complete information, there is no need to inefficiently distort entry. Entry gains can in turn be pocketed back by $I$ by setting a penalty for breach just equal to the price if trade occurs. This strategy ensures a constant payoff to $I$ and makes $B$ residual claimant for the decision to switch or not; a decision solely based on the comparison of her valuations with both suppliers.

It is worth noticing that the comparison with the spot market benchmark is somewhat artificial since, in this section, we have assumed symmetric information when $I$ offers $B$ a contract while asymmetric information prevails in the spot market scenario. This change in the information structure explains why $I$ always prefers contracting with $B$. That being said, the possibility of contracting provides $B$ with the same rent as in the spot market scenario, but the outcome is now socially efficient since $B$ switches to $E$ if and only if $v_{2} \geq v_{1}$.

\footnotetext{
${ }^{11}$ Integrating by parts, we obtain that $\left(v_{1}-p_{1}\right) G_{2}\left(v_{1}-\Delta\right)+\int_{v_{2} \geq v_{1}-\Delta}\left(v_{2}-p_{2}\right) d G_{2}\left(v_{2}\right)=v_{1}-p_{1}+$ $\int_{v_{2} \geq v_{1}-\Delta}\left(1-G_{2}\left(v_{2}\right)\right) d v_{2}$.
} 
In the next two sections, we analyze how asymmetric information (Section 4) and the allocation of bargaining power between $B$ and $E$ (Section 5 ) change those results.

\section{Contracts under Asymmetric Information}

We now turn to the situation where $B$ 's valuation for $I$ 's service is private information at stage 1 of the game. First, we find conditions that ensure $B$ does not misrepresent her valuation for the $I$ 's service. Second, we characterize $I$ 's optimal contract.

InCENTIVE COMPATIBILITY. The Revelation Principle ${ }^{12}$ allows us to restrict the analysis to direct and incentive-compatible revelation mechanisms of the form $\left(p_{1}\left(\hat{v}_{1}\right), \Delta\left(\hat{v}_{1}\right)\right)_{\hat{v}_{1} \in[0, \bar{v}]}$. Such a contract stipulates a menu of prices for trade and rebates for exclusivity which are contingent on $B$ 's report $\hat{v}_{1}$ on her valuation. Faced with such a menu, $B$ picks the one that maximizes her expected gain and obtains thereby an expected rent worth

$$
U_{B}\left(v_{1}\right)=\max _{\hat{v}_{1}} v_{1}-p_{1}\left(\hat{v}_{1}\right)+\int_{v_{2} \geq v_{1}-\Delta\left(\hat{v}_{1}\right)}\left(1-G_{2}\left(v_{2}\right)\right) d v_{2}
$$

Routine computations yield the following characterization of incentive-compatible contracts.

Lemma 2. A contract $\left(p_{1}\left(\hat{v}_{1}\right), \Delta\left(\hat{v}_{1}\right)\right)_{\hat{v}_{1} \in[0, \bar{v}]}$ is incentive-compatible if and only if it satisfies for all $v_{1} \in[0, \bar{v}]$

$$
\dot{U}_{B}\left(v_{1}\right)=G_{2}\left(v_{1}-\Delta\left(v_{1}\right)\right),
$$

and

$$
\dot{\Delta}\left(v_{1}\right) \leq 0 \text { a.e. }
$$

Lemma 2 shows that the rent profile of the buyer must be increasing with her own valuation $v_{1}$ (see Equation (4.2)). Intuitively, $B$ has some incentives to understate her valuation $v_{1}$ in order to reduce the price paid to $I .{ }^{13}$ To counter those incentives, $I$ must give up some information rent to buyers with high valuations. Finally, observe that buyers with higher valuations are more sensitive to a decrease in the probability of entry than buyers with lower valuations. In other words, the indifference curves of buyers in the $\left(\Delta, p_{1}\right)$-space have steeper slopes at higher valuations. As a result of this single-crossing condition, to be incentive-compatible and screen buyers according to their valuation, the profile of rebates must thus be non-increasing (Equation (4.3)).

Optimal CONTRACT. On top of the incentive constraints characterized in Lemma 2, the contract must also ensure that the buyer prefers, at stage 1, accepting I's offer rather than relying on the spot market or buying directly from $E$. This imposes the following

\footnotetext{
${ }^{12}$ Myerson (1982).

${ }^{13}$ One intuitive way to see this is to look at the price paid by $B$ under symmetric information, namely $p_{1}^{*}\left(v_{1}\right)=v_{1}+\int_{v_{2}>v_{1}}\left(1-G_{2}\left(v_{2}\right)\right) d v_{2}-U_{B}^{s m}\left(v_{1}\right)$. Then, we have $\dot{p}_{1}^{*}\left(v_{1}\right)=G_{2}\left(v_{1}\right)-G_{2}\left(v_{1}-p_{1}^{s m}\right)>0$. Therefore, $B$ has incentives to understate her valuation to lower the price paid to $I$.
} 
participation constraints $^{14}$

$$
U_{B}\left(v_{1}\right) \geq U_{B}^{s m}\left(v_{1}\right) \quad \forall v_{1} \in[0, \bar{v}]
$$

From the analyses undertaken in Sections 2 and 3, we conjecture that the optimal contract is characterized by a threshold $v_{1}^{*}$ (to be determined endogenously) such that:

- Buyers with valuations $v_{1} \leq v_{1}^{*}$ reject $I$ 's contract, and buy either from the spot market or directly from $E$;

- Buyers with valuations $v_{1} \geq v_{1}^{*}$ accept $I$ 's contract, and may switch later on depending on their valuation $v_{2}$ for $E$ 's service.

I's expected profit may then be rewritten as follows ${ }^{15}$

$$
\begin{aligned}
& \Pi_{I}=\int_{p_{1}^{s m}}^{v_{1}^{*}} p_{1}^{s m} G_{2}\left(v_{1}-p_{1}^{s m}\right) d G_{1}\left(v_{1}\right) \\
+ & \int_{v_{1}^{*}}^{\bar{v}}\left(v_{1}-\Delta\left(v_{1}\right)\left(1-G_{2}\left(v_{1}-\Delta\left(v_{1}\right)\right)\right)+\int_{v_{2} \geq v_{1}-\Delta\left(v_{1}\right)}\left(1-G_{2}\left(v_{2}\right)\right) d v_{2}-U_{B}\left(v_{1}\right)\right) d G_{1}\left(v_{1}\right)
\end{aligned}
$$

Indeed, a buyer with a valuation for $I$ 's service $v_{1}$ lower than $v_{1}^{*}$ goes to the spot market and, from the analysis undertaken in Section 2, buys from $I$ at a price $p_{1}^{s m}$ only when $v_{1} \geq v_{1}^{s m}$. Second, when $v_{1} \geq v_{1}^{*}$, the buyer accepts $I$ 's contract but decides to switch later on to the entrant when $v_{2} \geq v_{1}-\Delta\left(v_{1}\right)$.

I's problem is to maximize over $\left(v_{1}^{*}, \Delta\left(v_{1}\right), U_{B}\left(v_{1}\right)\right)$ his objective $\Pi_{I}$ subject to the incentive constraints (4.2) and (4.3), and the participation constraints (4.4). The next lemma describes some of key features of the optimal contract.

Proposition 2. Let $\tilde{v}_{1}$ be such that $p_{1}^{s m}=\frac{1-G_{1}\left(\tilde{v}_{1}\right)}{g_{1}\left(\tilde{v}_{1}\right)}$. First, $p_{1}^{s m} \leq \frac{1-G_{1}\left(p_{1}^{s m}\right)}{g_{1}\left(p_{1}^{s m}\right)}$, so that $\tilde{v}_{1} \geq p_{1}^{s m}$. Second, the optimal contract under asymmetric information is such that:

- Buyers with valuations $v_{1} \geq \tilde{v}_{1}$ receive a positive rebate for exclusivity

$$
\Delta^{s b}\left(v_{1}\right)=\frac{1-G_{1}\left(v_{1}\right)}{g\left(v_{1}\right)}
$$

- Buyers with valuations $v_{1} \leq \tilde{v}_{1}$ reject the contract and either buy from the spot market $\left(\tilde{v}_{1} \geq v_{1} \geq p_{1}^{s m}\right)$ or rely on the entrant only $\left(v_{1} \leq p_{1}^{s m}\right)$

The intuitions underlying Proposition 2 go as follows. First, as shown in Lemma 2, buyers are willing to understate their valuations. To make such a strategy less attractive, $I$ increases the rebate with respect to the symmetric information benchmark; i.e., $\Delta^{s b}\left(v_{1}\right) \geq \Delta^{*}\left(v_{1}\right)=0$ (with equality only for $v_{1}=\bar{v}$ ). Increasing the rebate implies

\footnotetext{
${ }^{14}$ Hence, participation constraints are type-dependent. In the Appendix, we show that the so called "net rent" $U_{B}\left(v_{1}\right)-U_{B}^{s m}\left(v_{1}\right)$ is increasing in $v_{1}$ so that participation constraints are binding for $v_{1}=v_{1}^{*}$ only. Jullien (2000) offers a general treatment of type-dependent participation constraints in adverse selection models.

${ }^{15} \mathrm{As}$ is usual, we express $I$ 's problem in terms of $\left(\Delta\left(v_{1}\right), U_{B}\left(v_{1}\right)\right)$ rather than in terms of $\left(p_{1}\left(v_{1}\right), p_{2}\left(v_{1}\right)\right)$.
} 
that the probability of entry increases. Indeed, by facilitating entry of the competing seller, $I$ discourages buyers with higher valuations for his service from understating their valuations, for this would imply to forego large gains from trade with $I$. Intuitively, the penalty $p_{2}$ allows to create a wedge between the price if the buyer buys from $I$ and if she buys from $E$. This wedge affects the gains from trade between the buyer and the entrant, which ultimately allows the incumbent to screen buyers according to their valuations. Excessive and socially inefficient entry arises, because $B$ switches when $v_{2} \geq v_{1}-\Delta^{s b}\left(v_{1}\right)$ with $v_{1}-\Delta^{s b}\left(v_{1}\right) \leq v_{1}$, as a way for the incumbent seller to reduce the buyer's information rent.

Asymmetric information also modifies participation. Only buyers with sufficiently large valuations $v_{1} \geq \tilde{v}_{1}$ accept the incumbent's contract, with $\tilde{v}_{1} \geq p_{1}^{s m}$ from the the first result in Lemma 2. Consequently, asymmetric information facilitates entry both at the intensive and at the extensive margins. At the intensive margin, those buyers who accept I's contract switch more often to $E$. At the extensive margin, those buyers with low valuations for the incumbent's service $\left(v_{1} \leq \tilde{v}_{1}\right)$ either buy directly from $E$ or from the spot market.

We can now discuss the impact of contracts with respect to the spot market scenario. Thanks to asymmetric information, $B$ earns more rent than with no contracts. More precisely, types $v_{1} \leq \tilde{v}_{1}$ earn the same level of rent than in the post market outcome, while types $v_{1} \geq \tilde{v}_{1}$ earn more rent. Although the outcome is no longer socially efficient under asymmetric information (except for the highest type $v_{1}=\bar{v}$ ), contracts tend to promote social efficiency as well.

Figure 2 represents the optimal contract under asymmetric information.

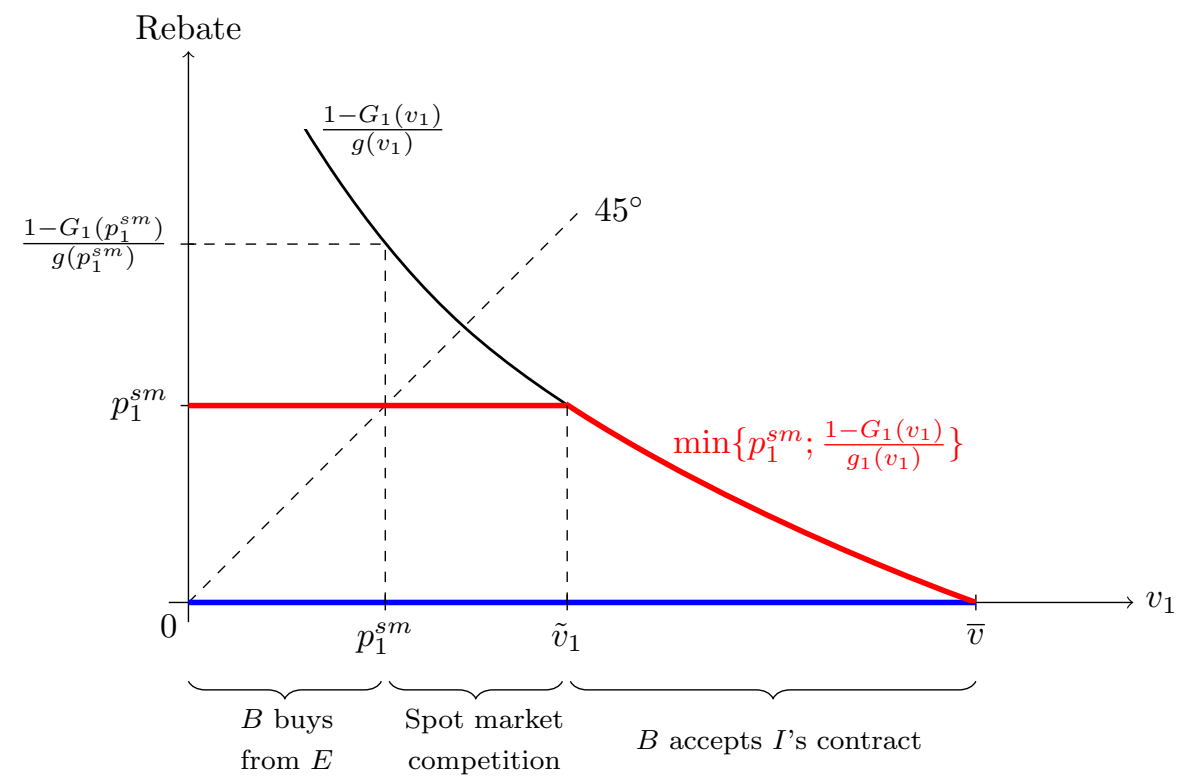

Figure 2: Optimal rebate under complete (blue) and asymmetric (red) information.

Last, coming back to the optimal prices $p_{1}$ and $p_{2}$ set by the incumbent, ${ }^{16}$ we observe that, with respect to the full information case, there is a now a strictly positive wedge

\footnotetext{
${ }^{16}$ See the proof of Proposition 2.
} 
$p_{1}-p_{2}>0$ for those types of buyer who accept the incumbent's contract, with both prices being strictly positive. Higher types obtain a lower price if they stay with $I$ but pay a higher penalty if they decide to switch to $E$.

\section{Bargaining Power}

We now relax the assumption that the buyer has all the bargaining power in her relationship with the entrant. We first show that, under symmetric information (Section 5.1), entry is now inefficiently reduced. We then consider the scenario of asymmetric information (Section 5.2) and show that there is a strong tension between efficiency and incentives, which sometimes leads to simple inflexible rules to decide on entry, i.e., bunching.

Before doing so, we first analyze the spot market outcome.

Spot market outcome. The analysis closely follows the approach undertaken in Section 2, the only difference being that if $B$ buys from $E$, then profits are determined according to the Nash bargaining solution with $B$ (resp. $E$ ) having bargaining power $\alpha$ (resp. $1-\alpha$ ), where $\alpha \in[0,1]$. This implies that $B$ 's and $E$ 's profits are the sum of their respective outside options and the share of the gains from trade corresponding to their bargaining power. To illustrate, if $B$ decides to switch to $E$, her profit is the sum of her outside option, namely $v_{1}-p_{1}$ (corresponding to the possibility of buying from $I$ ) and the share $\alpha$ of the gains from trade with $E$, namely $v_{2}-\left(v_{1}-p_{1}\right)$. Hence, at stage 3 of our game, $B$ switches to $E$ when $v_{1}-p_{1}+\alpha\left(v_{2}-v_{1}+p_{1}\right) \geq v_{1}-p_{1}$, i.e., when $v_{2} \geq v_{1}-p_{1}$. Consequently, $B$ 's expected gain from accepting $I$ 's price on the spot market is given by

$$
v_{1}-p_{1}+\alpha \int_{v_{2} \geq v_{1}-p_{1}}\left(v_{2}-v_{1}+p_{1}\right) d G_{2}\left(v_{2}\right)
$$

Since $B$ has still the possibility to turn down $I$ 's price and to buy directly from $E$, in which case she gets the share $\alpha$ of the gains from trade $v_{2}$, the buyer's spot market rent is given by

$$
\max \left\{v_{1}-p_{1}+\alpha \int_{v_{2} \geq v_{1}-p_{1}}\left(v_{2}-v_{1}+p_{1}\right) d G_{2}\left(v_{2}\right) ; \alpha \int v_{2} d G_{2}\left(v_{2}\right)\right\} .
$$

Proceeding as in Section 2, we obtain the following lemma.

Lemma 3. In the spot market, when $B$ has bargaining power $\alpha$ vis-à-vis $E$, I's optimal price is still given by $p_{1}^{\text {sm }}$ as characterized by (2.1). B accepts I's price if $v_{1} \geq p_{1}^{\text {sm }}$ and buys directly from $E$ otherwise.

The buyer's expected rent from the spot market is therefore given by

$$
U_{B}^{s m}\left(v_{1}\right)=\max \left\{v_{1}-p_{1}^{s m}+\alpha \int_{v_{2} \geq v_{1}-p_{1}^{s m}}\left(v_{2}-v_{1}+p_{1}^{s m}\right) d G_{2}\left(v_{2}\right) ; \alpha \int v_{2} d G_{2}\left(v_{2}\right)\right\} .
$$

\subsection{Contracts under Symmetric Information}

Let us now consider the case in which there is complete information on $v_{1}$ and $I$ offers a contract $\left(p_{1}\left(v_{1}\right), \Delta\left(v_{1}\right)\right)$ at stage 1 of our game. The analysis closely echoes that 
performed in Section 3. We simply note that the buyer's expected profit if she accepts the contract is now given by

$$
U_{B}\left(v_{1}\right)=v_{1}-p_{1}\left(v_{1}\right)+\alpha \int_{v_{2} \geq v_{1}-\Delta\left(v_{1}\right)}\left(v_{2}-v_{1}+\Delta\left(v_{1}\right)\right) d G_{2}\left(v_{2}\right)
$$

$B$ accepts $I$ 's contract provided that $U_{B}\left(v_{1}\right) \geq U_{B}^{s m}\left(v_{1}\right)$. The optimal rebate under complete information is characterized in the proposition below.

Proposition 3. Suppose there is symmetric information and $B$ has bargaining power $\alpha$ vis-à-vis $E$. Then, I offers a contract, which is always accepted by $B$, that involves a rebate for exclusivity $\Delta_{\alpha}^{*}\left(v_{1}\right)$ characterized by

$$
\Delta_{\alpha}^{*}\left(v_{1}\right)=-(1-\alpha) \frac{1-G_{2}\left(v_{1}-\Delta_{\alpha}^{*}\left(v_{1}\right)\right)}{g_{2}\left(v_{1}-\Delta_{\alpha}^{*}\left(v_{1}\right)\right)} .
$$

$\Delta_{\alpha}^{*}\left(v_{1}\right)$ is negative and increasing in $v_{1}$ and satisfies $\Delta_{\alpha}^{*}(\bar{v})=0$.

Figure 3 represents the optimal rebate $\Delta_{\alpha}^{*}\left(v_{1}\right)$ and compares this solution with the case in which the buyer has all the bargaining power (i.e., $\alpha=1$ ). Two comments are worth making.

First, the rebate is now negative. Indeed, when some of the gains from trade between $B$ and $E$ are kept by the entrant, entry is now reduced inefficiently by $I$ 's contract, which means $\Delta_{\alpha}^{*}\left(v_{1}\right) \leq 0$. This result echoes Aghion and Bolton (1987)'s insight that inefficient foreclosure arises when the incumbent seller cannot appropriate the gains associated to entry of the competing seller.

Second, the rebate now increases with the buyer's valuation $v_{1}$. Intuitively, buyers with higher valuations for $I$ 's service are less likely to switch to $E$, so that there is less reason to reduce inefficiently entry for those buyers.

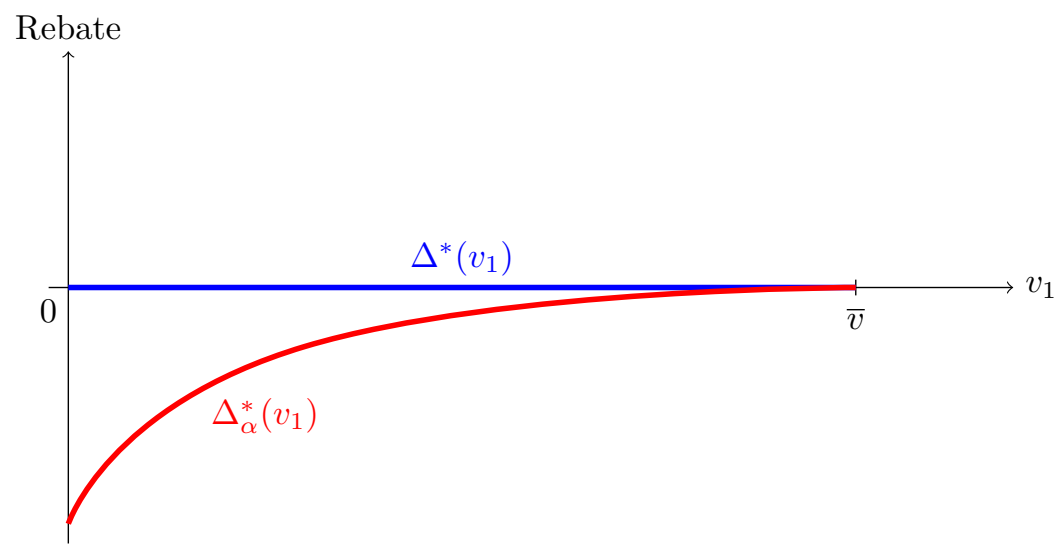

Figure 3: Optimal rebate under symmetric information: $\alpha=1$ (blue), $\alpha<1$ (red).

\subsection{Contracts under Asymmetric Information}

Let us now consider that $v_{1}$ is private information. Again, since the analysis follows closely that undertaken in Section 4, most of the technicalities are relegated to the Appendix. 
With asymmetric information, there is now a strong conflict between, on the one hand, efficiency, ${ }^{17}$ and, on the other hand, the provision of incentives. As stated in Proposition 3, efficiency commands to implement a profile of rebates that is increasing with the buyer's valuation for the incumbent's service. However, as shown in Lemma 2, incentive compatibility requires to implement a profile of rebates that is decreasing in $v_{1} \cdot{ }^{18}$ This extreme conflict between efficiency and incentives considerations may force $I$ to give up screening the different types of buyer and to offer a constant rebate to all those types. Put differently, full bunching may now emerge. ${ }^{19}$

To streamline the analysis, we study two polar cases. In the first setting, screening of the various buyers is always possible. In the second, all types of buyer are bunched altogether and the optimal rebate is constant.

Proposition 4. Suppose there is asymmetric information and $B$ has bargaining power $\alpha$ vis-à-vis $E$. Then, there exists a threshold $\tilde{v}_{1 \alpha}$ such that:

- Buyers with valuations $v_{1} \geq \tilde{v}_{1 \alpha}$ receive a rebate $\Delta_{\alpha}^{s b}\left(v_{1}\right)$ defined as

$$
\Delta_{\alpha}^{s b}\left(v_{1}\right)=\alpha \frac{1-G_{1}\left(v_{1}\right)}{g_{1}\left(v_{1}\right)}-(1-\alpha) \frac{1-G_{2}\left(v_{1}-\Delta_{\alpha}^{s b}\left(v_{1}\right)\right)}{g_{2}\left(v_{1}-\Delta_{\alpha}^{s b}\left(v_{1}\right)\right)}
$$

- Buyers with valuations $v_{1} \leq \tilde{v}_{1 \alpha}$ reject I's contract and either buy directly from $E$ or rely on the spot market.

This profile of rebates involves no bunching provided that

$$
\dot{\Delta}_{\alpha}^{s b}\left(v_{1}\right) \leq 0 \quad \forall v_{1} .
$$

Figure 4 represents optimal rebate profile $\Delta_{\alpha}^{s b}(\cdot)$, assuming Condition $(H)$ is satisfied. ${ }^{20}$

Under asymmetric information and shared bargaining power, the optimal rebate reflects the two effects already unveiled by our analysis. First, asymmetric information calls for increasing the rebate beyond its full information level, which promotes entry. This effect is captured by the first term in the right hand-side of Equation (5.2). Second, the shared bargaining power between $B$ and $E$ calls for decreasing the rebate, which reduces entry. This corresponds to the second term in the right hand-side of Equation (5.2). Provided that the compounding of these two effects keeps the rebate decreasing with the buyer's valuation $v_{1}$, so that the second-order conditions for incentive compatibility are still satisfied, the outcome is qualitatively similar to the one obtained when $B$ has full bargaining power vis-à-vis $E$. When $B$ 's valuation $v_{1}$ is low enough, she turns down $I$ 's contract and relies either on $E$ or on the spot market for her supplies. When $v_{1}$ is instead large enough, $B$ accepts $I$ 's contract and faces a positive rebate for exclusivity.

The rebate characterized in Equation (5.2) may not always satisfy the monotonicity requirement imposed by incentive compatibility, namely Condition $(H)$. Indeed, we have

\footnotetext{
${ }^{17}$ Efficiency refers to the incumbent seller's objective.

${ }^{18}$ Although Lemma 2 refers to the case $\alpha=1$, we show in Appendix A.7 that the same second-order condition for incentive compatibility must be satisfied when $\alpha<1$.

${ }^{19}$ See Lewis and Sappington (1989) for an earlier example of such inflexible rules in incentive problems and Guesnerie and Laffont (1984) for some general analysis.

${ }^{20}$ Observe that (5.2) leads to $\Delta_{\alpha}^{s b}(\bar{v})=0$. Therefore, under Condition $(H), \Delta_{\alpha}^{s b}\left(v_{1}\right) \geq 0$ for all $v_{1}$.
} 


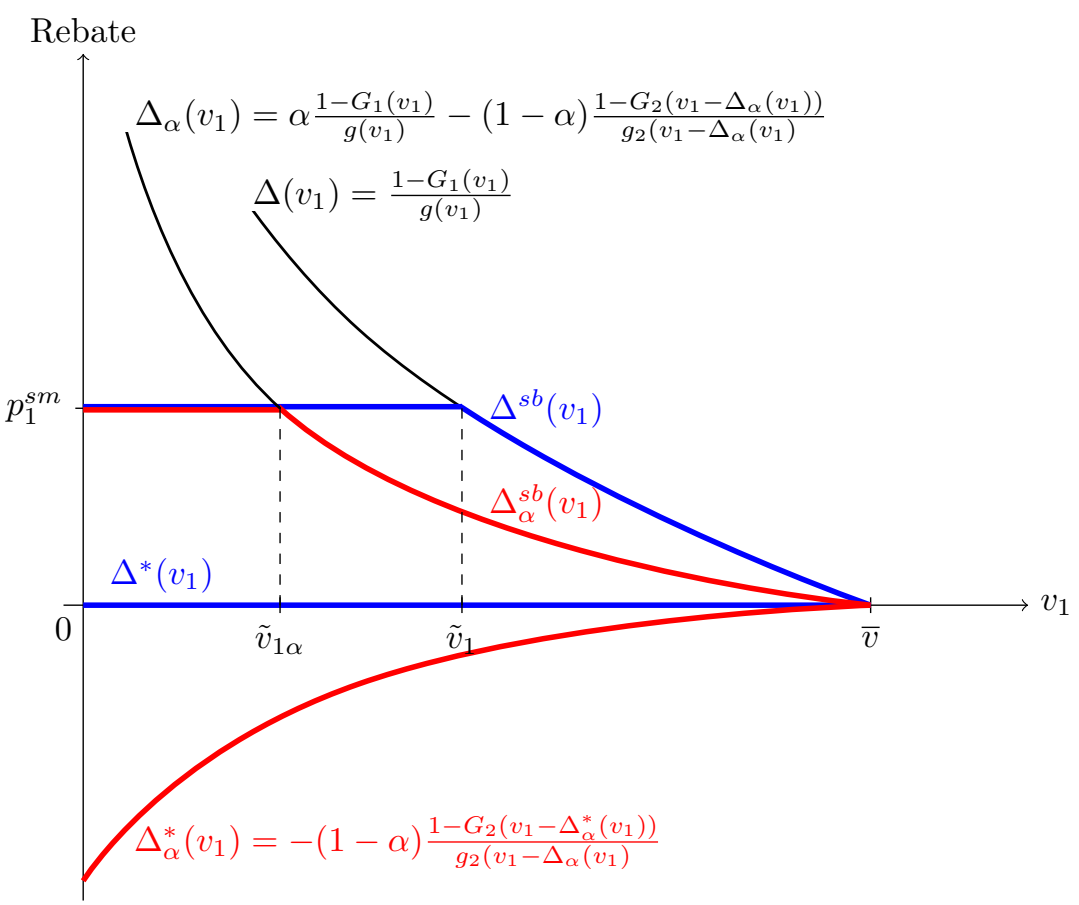

Figure 4: Optimal rebate under symmetric information and under asymmetric information when Condition $(H)$ is satisfied (no bunching): $\alpha=1$ (blue), $\alpha<1$ (red).

shown that promoting entry for incentive reasons leads to a decreasing rebate profile (Proposition 2). Foreclosing entry for efficiency reasons leads however to an increasing rebate profile (Proposition 3). When the latter effect is stronger than the former, the rebate profile $\Delta_{\alpha}^{s b}(\cdot)$ does not satisfy Condition $(H)$ and some bunching must occur. ${ }^{21}$

This is best illustrated in the case where $B$ has no bargaining power vis-à-vis $E$, or $\alpha=0:{ }^{22}$ the rebate $\Delta_{0}^{s b}\left(v_{1}\right)$ corresponding to Equation (5.2) is strictly increasing in $v_{1}$. As a result, bunching must occur, or, put differently, $I$ is led to offer a constant rebate to all types of buyers. We then obtain the following characterization of the optimal contract. $^{23}$

Proposition 5. Suppose there is asymmetric information and $B$ has no bargaining power vis-à-vis $E$ (that is, $\alpha=0$ ). Then, there exists $\tilde{v}_{10}$ such that:

- Buyers with valuations $v_{1} \geq \tilde{v}_{10}$ receive a constant negative rebate $\Delta_{0}^{s b}$ defined as

$$
\Delta_{0}^{s b}=-\frac{\int_{\tilde{v}_{10}}^{\bar{v}}\left(1-G_{2}\left(v_{1}-\Delta_{0}^{s b}\right)\right) d G_{1}\left(v_{1}\right)}{\int_{\tilde{v}_{10}}^{\bar{v}} g_{2}\left(v_{1}-\Delta_{0}^{s b}\right) d G_{1}\left(v_{1}\right)} ;
$$

- Buyers with valuations $v_{1} \leq \tilde{v}_{10}$ reject I's contract and either buy directly from $E$ or rely on the spot market.

\footnotetext{
${ }^{21}$ If valuation $v_{i}, i=1,2$, is distributed according to a distribution with linear hazard rate $\beta_{i}\left(\bar{v}-v_{i}\right)$, then Condition $(H)$ amounts to $\alpha \beta_{1} \geq(1-\alpha) \beta_{2}$, which holds when $B$ 's bargaining power vis-à-vis $E$ is sufficiently large.

${ }^{22}$ Notice, incidentally, that $\alpha=0$ corresponds to Aghion and Bolton (1987)'s assumption.

${ }^{23}$ In Appendix A.7, we characterize the optimal contract for all values of $\alpha$ when there is bunching for all types of buyer.
} 
Figure 5 compares the profile of rebates in the two polar cases of full bargaining power and no bargaining power.

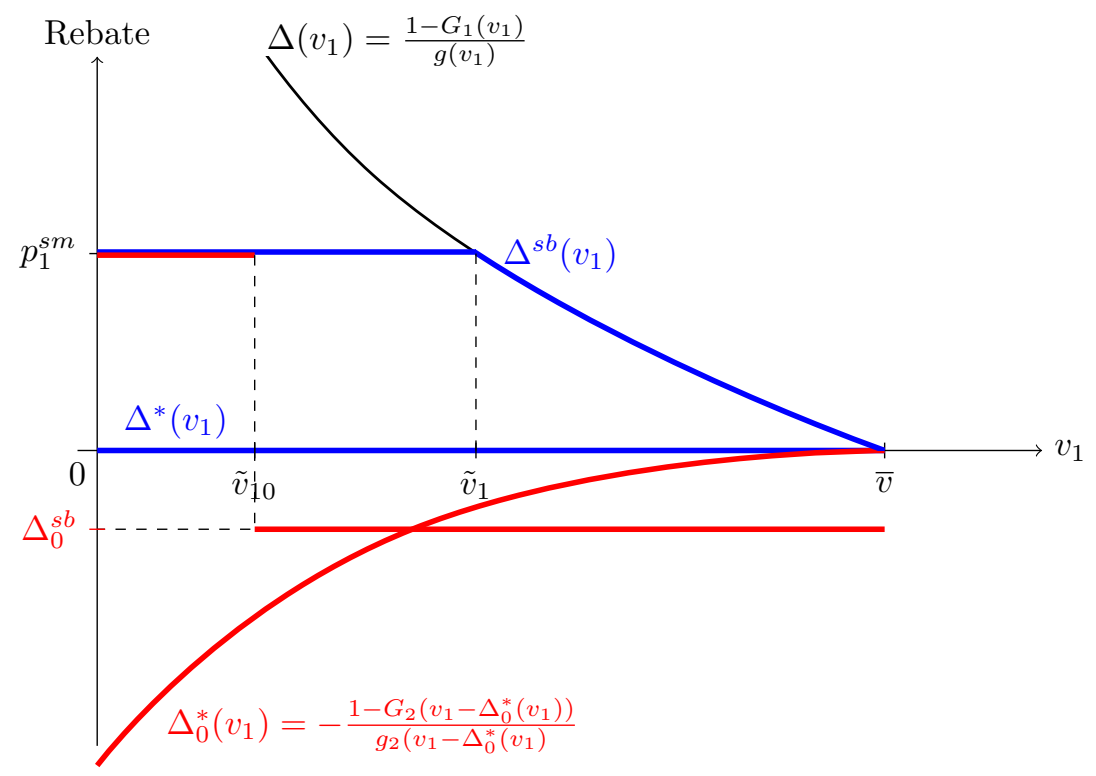

Figure 5: Optimal rebate under symmetric information and under asymmetric information when Condition $(H)$ is never satisfied: $\alpha=1$ (blue), $\alpha=0$ (red).

\section{Conclusion}

Aghion and Bolton (1987) have shown that a dominant seller tends to foreclose a more efficient competitor when the gains from trade associated to entry cannot be fully appropriated by the buyer and pocketed back by the dominant seller. From this starting point, we introduce some frictions in the relationship between the dominant seller and the buyer, which takes place now under asymmetric information. Asymmetric information calls instead for promoting (socially inefficient) entry in order to discourage buyers from understating their valuations for the incumbent's service. Therefore, asymmetric information between the dominant seller and the buyer tends to soften the antitrust concern about the foreclosure of more efficient rival sellers. We also show that when the buyer has a weak bargaining power vis-à-vis the entrant seller, the incumbent seller looses his ability to screen the various types of buyers and is led to offer a constant rebate that forecloses inefficiently entry.

Our analysis could be extended along several dimensions. For instance, we have assumed that the buyer has independent valuations for the incumbent's and the entrant's services. It may be worth investigating alternative frameworks in which these valuations are (imperfectly) correlated. In a similar vein, asymmetric information could endogenize how the gains from entry are shared between the buyer and the seller. This is left for future research.

\section{REFERENCES}

Abito, J. and J. Wright (2008). "Exclusive Dealing with Imperfect Downstream Competition," International Journal of Industrial Organization, 26: $227-246$. 
Aghion, P. and P. Bolton (1987). "Contracts as a Barrier to Entry," The American Economic Review, 77: 388-401.

Asker, J. and H. Bar-Isaac (2014). "Raising Retailers' Profits: On Vertical Practices and the Exclusion of Rivals," The American Economic Review, 104: $672-686$.

Bagnoli, M. and T. Bergstrom (2005). "Log-Concave Probability and its Applications," Economic Theory, 26: 445-469.

Bedre-Defolie, Ö. and G. Biglaiser (2017). "Contracts as a Barrier to Entry in Markets with Nonpivotal Buyers," The American Economic Review, 107: 2041-2071.

Bork, R. (1978). The Antitrust Paradox, Basic Books.

Calzolari, G. and V. Denicolò (2013). "Competition with Exclusive Contracts and Market-Share Discounts," The American Economic Review, 103: 2384-2411.

Calzolari, G. and V. Denicolò (2015). "Exclusive Contracts and Market Dominance," The American Economic Review, 105: 3321-3351.

Chen, Z. and G. Shaffer (2014). "Naked Exclusion with Minimum-Share Requirements," The RAND Journal of Economics, 45: 64-91.

Chen, Z. and G. Shaffer (2019). "Market Share Contracts, Exclusive Dealing, and the Integer Problem," American Economic Journal: Microeconomics, 11: $208-42$.

Choné, P. and L. Linnemer (2015). "Nonlinear Pricing and Exclusion: I. Buyer Opportunism," The RAND Journal of Economics, 46: 217-240.

Choné, P. and L. Linnemer (2016). "Nonlinear Pricing and Exclusion: II. Must-stock Products," The RAND Journal of Economics, 47: 631-660.

Fumagalli, C. and M. Motta (2006). "Exclusive Dealing and Entry, When Buyers Compete," The American Economic Review, 96: 785-95.

Guesnerie, R. and J.-J. Laffont (1984). "A Complete Solution to a Class of Principal-Agent Problems with an Application to the Control of a SelfManaged Firm," Journal of Public Economics, 25: 329-369.

Ide, E., J.-P. Montero, and N. Figueroa (2016). "Discounts as a Barrier to Entry." American Economic Review, 106(7): 1849-77.

Innes, R. and R. Sexton (1994). "Strategic Buyers and Exclusionary Contracts," The American Economic Review, 84: 566-584.

Jullien, B. (2000). "Participation Constraints in Adverse Selection Models," Journal of Economic Theory, 93(1): 1-47.

Laffont, J.-J. and D. Martimort (2002). The Theory of Incentives, Princeton University Press.

Lewis, T. and D. Sappington (1989). "Inflexible Rules in Incentive Problems." The American Economic Review, 79: 69-84.

Martimort, D., J. Pouyet and L. Stole (2017). "Screening Contracts as a Barrier to Entry," mimeo. 
Marx, L. and G. Shaffer (1999). "Predatory Accommodation: Below-Cost Pricing without Exclusion in Intermediate Goods Markets." The RAND Journal of Economics, 30(1): 22-43.

Marx, L. and G. Shaffer (2004). "Rent-Shifting, Exclusion, and Market-Share Discounts," mimeo.

Myerson, R. (1982). "Optimal Coordination Mechanisms in Generalized PrincipalAgent Models," Journal of Mathematical Economics, 10: 67-81.

Posner, R. (1976). Antitrust Law: An Economic Perspective, University of Chicago Press.

Rasmusen, E., J.M. Ramseyer and J. Wiley (1991). "Naked Exclusion," The American Economic Review, 81: 1137-45.

Segal, I. and M. Whinston (2000). "Naked Exclusion: Comment," The American Economic Review, 90: 296-309.

Simpson, J. and A. Wickelgren (2007). "Naked Exclusion, Efficient Breach, and Downstream Competition," The American Economic Review, 97: 13051320 .

Spector, D. (2011). "Exclusive Contracts and Demand Foreclosure," The RAND Journal of Economics, 42: 619-638.

Wright, J. (2009). "Exclusive Dealing and Entry, When Buyers Compete: Comment." The American Economic Review, 99: 1070-81. 


\section{A. Appendix}

\section{A.1. Proof of Lemma 1}

Notice that $\left(v_{1}-p_{1}\right) G_{2}\left(v_{1}-p_{1}\right)+\int_{v_{2} \geq v_{1}-p_{1}} v_{2} d G_{2}\left(v_{2}\right) \geq \int v_{2} d G_{2}\left(v_{2}\right)$ amounts to

$$
\left(v_{1}-p_{1}\right) G_{2}\left(v_{1}-p_{1}\right) \geq \int_{v_{2} \leq v_{1}-p_{1}} v_{2} d G_{2}\left(v_{2}\right) .
$$

Let $\varphi(x): x \mapsto x G_{2}(x)-\int_{0}^{x} v_{2} d G_{2}\left(v_{2}\right)$. It is straightforward to show that $\varphi^{\prime}(x) \geq 0 \forall x$ and $\varphi(0)=0$. Therefore, (A.1) is satisfied iff $v_{1} \geq p_{1}$.

\section{A.2. Proof of Proposition 1}

From Lemma 1, we know that $U_{B}^{s m}\left(v_{1}\right)=\int v_{2} d G_{2}\left(v_{2}\right)$ if $v_{1} \leq p_{1}^{s m}$ and $U_{B}^{s m}\left(v_{1}\right)=v_{1}-p_{1}^{s m}+$ $\int_{v_{2} \geq v_{1}-p_{1}^{s m}}\left(v_{2}-v_{1}+p_{1}^{s m}\right) d G_{2}\left(v_{2}\right)$ if $v_{1} \geq p_{1}^{s m}$.

The participation constraint must bind at the optimum for, otherwise, $I$ could raise his price $p_{1}\left(v_{1}\right)$ and $p_{2}\left(v_{1}\right)$ by the same small positive amount, which would increase his profit. ${ }^{24}$ $I$ 's problem becomes thus

$$
\max _{\Delta\left(v_{1}\right)} v_{1}+\int_{v_{2} \geq v_{1}-\Delta\left(v_{1}\right)}\left(1-G_{2}\left(v_{2}\right)\right) d v_{2}-\Delta\left(v_{1}\right)\left(1-G_{2}\left(v_{1}-\Delta\left(v_{1}\right)\right)\right)-U_{B}^{s m}\left(v_{1}\right) .
$$

The first-order condition writes as follows

$$
-\Delta\left(v_{1}\right) g_{2}\left(v_{1}-\Delta\left(v_{1}\right)\right)=0
$$

which holds iff $\Delta\left(v_{1}\right)=0$. Observe that this condition also shows that the objective is increasing in $\Delta\left(v_{1}\right)$ for $\Delta\left(v_{1}\right) \leq 0$ and decreasing in $\Delta\left(v_{1}\right)$ for $\Delta\left(v_{1}\right) \geq 0$. Hence, the objective is quasiconcave in $\Delta\left(v_{1}\right)$, and the first-order condition is both necessary and sufficient.

When $v_{1} \leq p_{1}^{s m}, I$ 's profit when using a contract is thus equal to $v_{1}+\int_{v_{2} \geq v_{1}}\left(v_{2}-v_{1}\right) d G_{2}\left(v_{2}\right)-$ $\int v_{2} d G_{2}\left(v_{2}\right) \geq 0$ (with a strict inequality as soon as $v_{1}>0$ ). Hence, $I$ offers a contract.

When $v_{1} \geq p_{1}^{s m}, I$ 's payoff is $v_{1}+\int_{v_{2} \geq v_{1}}\left(1-G_{2}\left(v_{2}\right)\right) d v_{2}-\left(v_{1}-p_{1}^{s m}+\int_{v_{2} \geq v_{1}-p_{1}^{s m}}\left(v_{2}-v_{1}+\right.\right.$ $\left.\left.p_{1}^{s m}\right) d G_{2}\left(v_{2}\right)\right)$ when using a contract. If $I$ does not use a contract and relies on the spot market only, his gain is $\max _{p_{1}} \int_{v_{2} \geq p_{1}} p_{1} G_{2}\left(v_{1}-p_{1}\right) d G_{2}\left(v_{2}\right)$. Therefore, $I$ prefers using a contract iff

$$
v_{1}+\int_{v_{2} \geq v_{1}}\left(1-G_{2}\left(v_{2}\right)\right) d v_{2} \geq U_{B}^{m}\left(v_{1}\right)+\max _{p_{1}} \int_{v_{2} \geq p_{1}} p_{1} G_{2}\left(v_{1}-p_{1}\right) d G_{2}\left(v_{2}\right),
$$

which holds since the left-hand side is the joint surplus of $I$ and $B$ maximized over $p_{1}\left(v_{1}\right)$ and $p_{2}\left(v_{1}\right)$, whereas the right-hand side is the joint surplus of $I$ and $B$ when $p_{1}\left(v_{1}\right)$ is set to maximize I's profit only.

\section{A.3. Proof of Lemma 2}

Let $U_{B}\left(v_{1}, \hat{v}_{1}\right)=v_{1}-p_{1}\left(\hat{v}_{1}\right)+\int_{v_{2} \geq v_{1}-\Delta\left(\hat{v}_{1}\right)}\left(1-G_{2}\left(v_{2}\right)\right) d v_{2}$ be the expected gain of a buyer with type $v_{1}$ who claims to be of type $\hat{v}_{1}$. The local first- and second-order conditions for truthful reporting are

$$
\left.\frac{\partial U_{B}}{\partial \hat{v}_{1}}\left(v_{1}, \hat{v}_{1}\right)\right|_{\hat{v}_{1}=v_{1}}=0 \quad \text { and }\left.\quad \frac{\partial^{2} U_{B}}{\partial \hat{v}_{1}^{2}}\left(v_{1}, \hat{v}_{1}\right)\right|_{\hat{v}_{1}=v_{1}} \leq 0 .
$$

\footnotetext{
${ }^{24}$ See Laffont and Martimort (2002) for instance.
} 
Using $B$ 's expected gain as given by (4.1), the two conditions above can be rewritten as (4.2) and (4.3) respectively.

Global incentive compatibility for the type- $v_{1}$ buyer requires that for all $\hat{v}_{1}$

$\left(I C_{v_{1}}\right) \quad U_{B}\left(v_{1}\right) \geq U_{B}\left(v_{1}, \hat{v}_{1}\right)=U_{B}\left(\hat{v}_{1}\right)+\left(v_{1}-\hat{v}_{1}\right)+\varphi\left(v_{1}, \Delta\left(\hat{v}_{1}\right)\right)-\varphi\left(\hat{v}_{1}, \Delta\left(\hat{v}_{1}\right)\right)$,

where $\varphi\left(v_{1}, \Delta\right)=\int_{v_{2} \geq v_{1}-\Delta}\left(1-G_{2}\left(v_{2}\right)\right) d v_{2}$. Summing constraints $\left(I C_{v_{1}}\right)$ and $\left(I C_{\hat{v}_{1}}\right)$ leads to

$$
\varphi\left(v_{1}, \Delta\left(v_{1}\right)\right)-\varphi\left(\hat{v}_{1}, \Delta\left(v_{1}\right)\right) \geq \varphi\left(v_{1}, \Delta\left(\hat{v}_{1}\right)\right)-\varphi\left(\hat{v}_{1}, \Delta\left(\hat{v}_{1}\right)\right),
$$

which can be rewritten as

$$
\int_{\hat{v}_{1}}^{v_{1}} \int_{\Delta\left(\hat{v}_{1}\right)}^{\Delta\left(v_{1}\right)} \frac{\partial^{2} \varphi}{\partial v_{1} \partial \Delta} d \Delta d v_{1} \geq 0
$$

Observe now that $\frac{\partial^{2} \varphi}{\partial v \partial \Delta}=-g_{2}\left(v_{1}-\Delta\right) \leq 0$. Therefore, provided that $\Delta(\cdot)$ is non-decreasing, the menu of contracts is globally incentive compatible.

\section{A.4. Proof of Proposition 2}

First, integrating by parts the numerator, (2.1) can be rewritten as follows

$$
p_{1}^{s m}=\frac{\int_{v_{1} \geq p_{1}^{s m}} g_{2}\left(v_{1}-p_{1}^{s m}\right)\left(1-G_{1}\left(v_{1}\right)\right) d v_{1}}{\int_{v_{1} \geq p_{1}^{s m}} g_{2}\left(v_{1}-p_{1}^{s m}\right) g_{1}\left(v_{1}\right) d v_{1}} .
$$

Since $G_{1}$ satisfies the monotone hazard rate property, $\frac{1-G_{1}\left(v_{1}\right)}{g\left(v_{1}\right)} \leq \frac{1-G_{1}\left(p_{1}^{s m}\right)}{g\left(p_{1}^{s m}\right)}$ for all $v_{1} \geq p_{1}^{s m}$. Therefore

$$
\begin{aligned}
p_{1}^{s m} & \leq \frac{\int_{v_{1} \geq p_{1}^{s m}} g_{2}\left(v_{1}-p_{1}^{s m}\right) g_{1}\left(v_{1}\right) \frac{1-G_{1}\left(p_{1}^{s m}\right)}{g_{1}\left(p_{1}^{s m}\right)} d v_{1}}{\int_{v_{1} \geq p_{1}^{s m}} g_{2}\left(v_{1}-p_{1}^{s m}\right) g_{1}\left(v_{1}\right) d v_{1}} \\
& =\frac{1-G_{1}\left(p_{1}^{s m}\right)}{g_{1}\left(p_{1}^{s m}\right)} .
\end{aligned}
$$

This proves the first result. Notice that the inequality is strict as soon as $v_{1}>p_{1}^{s m}$.

Second, from (4.2), the rent profile $U_{B}(\cdot)$ must be non-decreasing in $v_{1}$. Observe also that for $v_{1} \geq p_{1}^{s m}, \dot{U}_{B}^{s m}\left(v_{1}\right)=G_{2}\left(v_{1}-p_{1}^{s m}\right)$. Consequently, $\dot{U}_{B}\left(v_{1}\right)-\dot{U}_{B}^{s m}\left(v_{1}\right)=G_{2}\left(v_{1}-\Delta\left(v_{1}\right)\right)-$ $G_{2}\left(v_{1}-p_{1}^{s m}\right)$. Let us assume for the moment, and check later on, that $\Delta\left(v_{1}\right) \leq p_{1}^{s m}$. This implies that $\dot{U}_{B}\left(v_{1}\right)-\dot{U}_{B}^{s m}\left(v_{1}\right) \geq 0$ so that (4.4) can be replaced by $U_{B}\left(v_{1}^{*}\right) \geq U_{B}^{s m}\left(v_{1}^{*}\right)$. That constraint must bind at the optimum, or $U_{B}\left(v_{1}^{*}\right)=U_{B}^{s m}\left(v_{1}^{*}\right)$. Using this and (4.2), B's rent may be written as follows

$$
U_{B}\left(v_{1}\right)=U_{B}^{s m}\left(v_{1}^{*}\right)+\int_{v_{1}^{*}}^{v_{1}} G_{2}(x-\Delta(x)) d x
$$

which allows in turn to express $B$ 's expected rent as follows

$$
\int_{v_{1}^{*}}^{\bar{v}} U_{B}\left(v_{1}\right) d G_{1}\left(v_{1}\right)=U_{B}^{s m}\left(v_{1}^{*}\right)\left(1-G_{1}\left(v_{1}^{*}\right)\right)+\int_{v_{1}^{*}}^{\bar{v}} G_{2}\left(v_{1}-\Delta\left(v_{1}\right)\right) \frac{1-G_{1}\left(v_{1}\right)}{g_{1}\left(v_{1}\right)} d G_{1}\left(v_{1}\right) .
$$


We can use this expression of $B$ 's expected rent to rewrite $I$ 's objective as follows

$$
\begin{aligned}
& \int_{p_{1}^{s m}}^{v_{1}^{*}} p_{1}^{s m} G_{2}\left(v_{1}-p_{1}^{s m}\right) d G_{1}\left(v_{1}\right)-U_{B}^{s m}\left(v_{1}^{*}\right)\left(1-G_{1}\left(v_{1}^{*}\right)\right) \\
+ & \int_{v_{1}^{*}}^{\bar{v}}\left(v_{1}-\Delta\left(v_{1}\right)\left(1-G_{2}\left(v_{1}-\Delta\left(v_{1}\right)\right)\right)+\int_{v_{2} \geq v_{1}-\Delta\left(v_{1}\right)}\left(1-G_{2}\left(v_{2}\right)\right) d v_{2}-G_{2}\left(v_{1}-\Delta\left(v_{1}\right)\right) \frac{1-G_{1}\left(v_{1}\right)}{g_{1}\left(v_{1}\right)}\right) d G_{1}\left(v_{1}\right),
\end{aligned}
$$

which has to be maximized over $v_{1}^{*}$ and $\Delta\left(v_{1}\right)$.

Pointwise optimization on $\left[v_{1}^{*}, \bar{v}\right]$ leads to the following first-order condition $\Delta^{s b}\left(v_{1}\right)=$ $\frac{1-G_{1}\left(v_{1}\right)}{g\left(v_{1}\right)}$. The second-order condition is $-g_{2}^{\prime}\left(v_{1}-\Delta\left(v_{1}\right)\right)\left(\Delta\left(v_{1}\right)+\frac{1-G_{1}\left(v_{1}\right)}{g\left(v_{1}\right)}\right)-g_{2}\left(v_{1}-\Delta\left(v_{1}\right)\right) \leq 0$. That condition holds locally for $\Delta\left(v_{1}\right)=\Delta^{s b}\left(v_{1}\right)$ and globally if $g_{2}^{\prime}$ is negligible w.r.t. $g_{2}$ for instance.

The first-order condition w.r.t. $v_{1}^{*}$ yields (using the fact that $\left.\Delta^{s b}\left(v_{1}^{*}\right)=\frac{1-G_{1}\left(v_{1}^{*}\right)}{g_{1}\left(v_{1}^{*}\right)}\right)$

$$
\begin{aligned}
v_{1}^{*}-\Delta^{s b}\left(v_{1}^{*}\right)+\int_{v_{1}^{*}-\Delta^{s b}\left(v_{1}^{*}\right)}^{\bar{v}}(1- & \left.G_{2}\left(v_{2}\right)\right) d v_{2} \\
& =p_{1}^{s m} G_{2}\left(v_{1}^{*}-p_{1}^{s m}\right)-\dot{U}_{B}^{s m}\left(v_{1}^{*}\right) \frac{1-G_{1}\left(v_{1}^{*}\right)}{g_{1}\left(v_{1}^{*}\right)}+U_{B}^{s m}\left(v_{1}^{*}\right) .
\end{aligned}
$$

Now, let $\tilde{v}_{1}$ be such that $p_{1}^{s m}=\frac{1-G_{1}\left(\tilde{v}_{1}\right)}{g_{1}\left(\tilde{v}_{1}\right)}$. We have $\tilde{v}_{1} \geq p_{1}^{s m}$ from our first result. Observe that $\left(\tilde{v}_{1}-p_{1}^{s m}\right) G_{2}\left(\tilde{v}_{1}-p_{1}^{s m}\right)+\int_{\tilde{v}_{1}-p_{1}^{s m}}^{\bar{v}} v_{2} d G_{2}\left(v_{2}\right)=\left(\tilde{v}_{1}-p_{1}^{s m}\right)+\int_{\tilde{v}_{1}-p_{1}^{s m}}^{\bar{v}}\left(1-G_{2}\left(v_{2}\right)\right) d v_{2}$ and that $\left(\tilde{v}_{1}-p_{1}^{s m}\right)+\int_{\tilde{v}_{1}-p_{1}^{s m}}^{\bar{v}}\left(1-G_{2}\left(v_{2}\right)\right) d v_{2} \geq \int_{0}^{\bar{v}} v_{2} d G_{2}\left(v_{2}\right)$ (since the function $x \mapsto \varphi(x)=x+\int_{x}^{\bar{v}}(1-$ $\left.G_{2}\left(v_{2}\right)\right) d v_{2}$ is increasing in $x$ with $\left.\varphi(0)>0\right)$. Therefore, we have $\dot{U}_{B}^{s m}\left(\tilde{v}_{1}\right)=G_{2}\left(\tilde{v}_{1}-p_{1}^{s m}\right)$.

It is then straightforward to show that the first-order condition (A.2) is satisfied at $v_{1}^{*}=\tilde{v}_{1}$. Last, for all $v_{1} \geq v_{1}^{*}=\tilde{v}_{1}, \Delta^{s b}\left(v_{1}\right) \leq \Delta^{s b}\left(v_{1}^{*}\right)=\Delta^{s b}\left(\tilde{v}_{1}\right)=p_{1}^{s m}$.

Let us now compare the optimal prices $p_{1}$ and $p_{2}$ under complete information and under asymmetric information. Under complete information, optimal prices are given by (using the optimality condition $\Delta^{*}\left(v_{1}\right)=0$ and the binding participation constraint $\left.U_{B}\left(v_{1}\right)=U_{B}^{s m}\left(v_{1}\right)\right)$

$$
p_{1}^{*}\left(v_{1}\right)=p_{2}^{*}\left(v_{1}\right)=v_{1}-U_{B}^{s m}\left(v_{1}\right)+\int_{v_{2} \geq v_{1}}\left(1-G_{2}\left(v_{2}\right)\right) d v_{2} .
$$

From (A.3), we obtain $\dot{p}_{1}^{*}\left(v_{1}\right)=\dot{p}_{2}^{*}\left(v_{1}\right)=G_{2}\left(v_{1}\right)-G_{2}\left(v_{1}-p_{1}^{s m}\right)>0$.

Under asymmetric information, optimal prices are characterized by (with $\left.\Delta^{s b}\left(v_{1}\right)=\frac{1-G_{1}\left(v_{1}\right)}{g_{1}\left(v_{1}\right)}\right)$

$$
\begin{aligned}
& p_{2}^{s b}\left(v_{1}\right)=p_{1}^{s b}\left(v_{1}\right)-\Delta^{s b}\left(v_{1}\right), \\
& p_{1}^{s b}\left(v_{1}\right)=v_{1}-U_{B}^{s m}\left(\tilde{v}_{1}\right)-\int_{\tilde{v}_{1}}^{v_{1}} G_{2}(x-\Delta(x)) d x+\int_{v_{2} \geq v_{1}-\Delta^{s b}\left(v_{1}\right)}\left(1-G_{2}\left(v_{2}\right)\right) d v_{2} .
\end{aligned}
$$

From (A.4) and (A.5), we obtain $\dot{p}_{1}^{s b}\left(v_{1}\right)=\dot{\Delta}^{s b}\left(v_{1}\right)\left(1-G_{2}\left(v_{1}-\Delta^{s b}\left(v_{1}\right)\right)\right)<0$ and $\dot{p}_{2}^{s b}\left(v_{1}\right)=$ $\left.-\dot{\Delta}^{s b}\left(v_{1}\right) G_{2}\left(v_{1}-\Delta^{s b}\left(v_{1}\right)\right)\right)>0$. Remember that $p_{1}^{s b}(\bar{v})-p_{2}^{s b}(\bar{v})=\Delta^{s b}(\bar{v})=0$. It also comes that

$$
p_{1}^{s b}\left(\tilde{v}_{1}\right)-p_{1}^{*}\left(\tilde{v}_{1}\right)=\int_{\tilde{v}_{1}-\Delta^{s b}\left(\tilde{v}_{1}\right)}^{\tilde{v}_{1}}\left(1-G_{2}\left(v_{2}\right)\right) d v_{2}>0 .
$$

Notice also that

$$
p_{2}^{s b}\left(\tilde{v}_{1}\right)-p_{2}^{*}\left(\tilde{v}_{1}\right)=\int_{\tilde{v}_{1}-\Delta^{s b}\left(\tilde{v}_{1}\right)}^{\tilde{v}_{1}}\left(1-G_{2}\left(v_{2}\right)\right) d v_{2}-\Delta^{s b}\left(\tilde{v}_{1}\right) .
$$


Define $f(x)=\int_{x-\Delta^{s b}(x)}^{x}\left(1-G_{2}\left(v_{2}\right)\right) d v_{2}-\Delta^{s b}(x)$. We have $f(\bar{v})=0$ since $\Delta^{s b}(\bar{v})=0$. We also have $f^{\prime}(x)=-\dot{\Delta}^{s b}(x) G_{2}\left(x-\Delta^{s b}(x)\right)>0$. Therefore $f\left(\tilde{v}_{1}\right) \leq 0$ for all $\tilde{v}_{1} \leq \bar{v}$. Therefore

$$
p_{2}^{s b}\left(\tilde{v}_{1}\right)-p_{2}^{*}\left(\tilde{v}_{1}\right)<0 .
$$

From these results, we can deduce the following graphical representation of the optimal prices under complete and asymmetric information (reminding that, by definition, $p_{1}^{s b}\left(v_{1}\right)-p_{2}^{s b}\left(v_{1}\right)=$ $\left.\Delta^{s b}\left(v_{1}\right)\right)$.

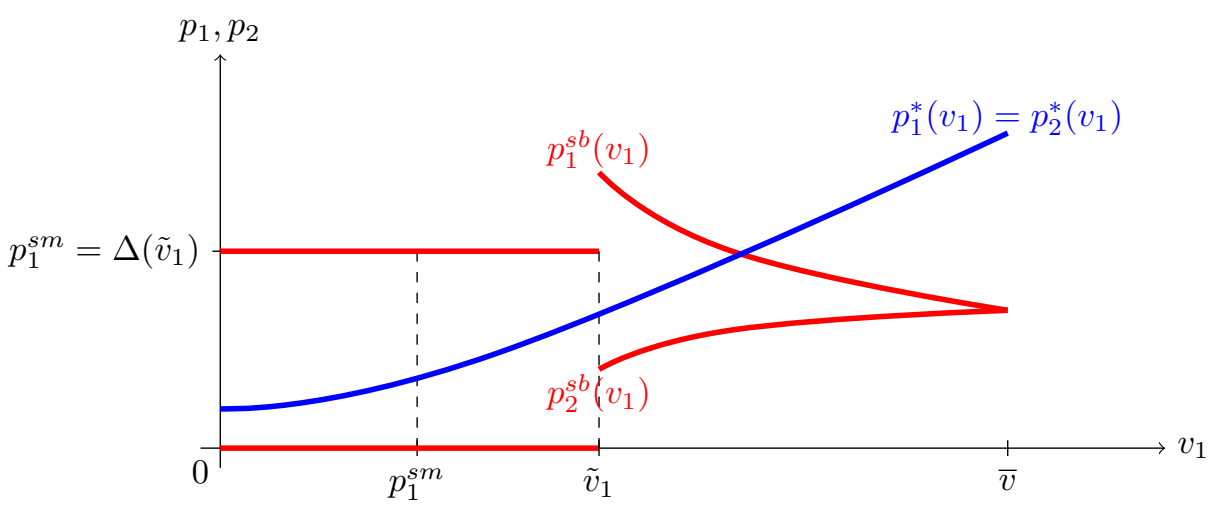

Figure 6: Optimal prices $\left(p_{1}, p_{2}\right)$ under complete (blue) and asymmetric (red) information.

\section{A.5. Proof of Lemma 3}

Notice that $v_{1}-p_{1}+\alpha \int_{v_{2} \geq v_{1}-p_{1}}\left(v_{2}-v_{1}+p_{1}\right) d G_{2}\left(v_{2}\right) \geq \alpha \int v_{2} d G_{2}\left(v_{2}\right)$ amounts to

$$
\left(v_{1}-p_{1}\right)\left[G_{2}\left(v_{1}-p_{1}\right)+(1-\alpha)\left(1-G_{2}\left(v_{1}-p_{1}\right)\right)\right]-\alpha \int_{v_{1} \leq v_{1}-p_{1}} v_{2} d G_{2}\left(v_{2}\right) \geq 0 .
$$

The function $x \mapsto \varphi(x)=x\left[G_{2}(x)+(1-\alpha)\left(1-G_{2}(x)\right)\right]-\alpha \int_{v_{1} \leq x} v_{2} d G_{2}\left(v_{2}\right)$ is increasing in $x \geq 0$ is takes value 0 at $x=0$. Therefore, $B$ accepts $I$ 's price iff $v_{1} \geq p_{1}$.

I's profit is thus given by $\int_{v_{1} \geq p_{1}} p_{1} G_{2}\left(v_{1}-p_{1}\right) d G_{1}\left(v_{1}\right)$, and is maximized for $p_{1}=p_{1}^{s m}$.

\section{A.6. Proof of Proposition 3}

I's problem is to maximize over $\left(p_{1}\left(v_{1}\right), \Delta\left(v_{1}\right)\right)$ his expected profit $p_{1}\left(v_{1}\right)-\Delta\left(v_{1}\right)(1-$ $\left.G_{2}\left(v_{1}-\Delta\left(v_{1}\right)\right)\right)$ subject to the participation constraint $v_{1}-p_{1}\left(v_{1}\right)+\alpha \int_{v_{2} \geq v_{1}-\Delta\left(v_{1}\right)}\left(v_{2}-v_{1}+\right.$ $\left.\Delta\left(v_{1}\right)\right) d G_{2}\left(v_{2}\right) \geq U_{B}^{s m}\left(v_{1}\right)$. The price $p_{1}\left(v_{1}\right)$ is such that the participation constraint binds. Replacing in $I$ 's objective and optimizing w.r.t. $\Delta\left(v_{1}\right)$ leads to the following first-order condition

$$
-\Delta\left(v_{1}\right) g_{2}\left(v_{1}-\Delta\left(v_{1}\right)\right)-(1-\alpha)\left(1-G_{2}\left(v_{1}-\Delta\left(v_{1}\right)\right)\right)=0,
$$

which leads to (5.1) after rearranging terms. Notice that $\psi: \Delta \mapsto \psi(\Delta)=-\Delta-(1-\alpha)(1-$ $\left.G_{2}\left(v_{1}-\Delta\right)\right) / g_{2}\left(v_{1}-\Delta\right)$ is such that $\psi^{\prime}(\Delta)<0$, so that the objective is quasi-concave in $\Delta$.

Totally differentiating (5.1) w.r.t. $v_{1}$ leads to

$$
\dot{\Delta}_{\alpha}^{*}\left(v_{1}\right)\left(1-\left.(1-\alpha)\left(\frac{d}{d v_{2}} \frac{1-G_{2}\left(v_{2}\right)}{g_{2}\left(v_{2}\right)}\right)\right|_{v_{1}-\Delta_{\alpha}^{*}\left(v_{1}\right)}\right)=-\left.(1-\alpha)\left(\frac{d}{d v_{2}} \frac{1-G_{2}\left(v_{2}\right)}{g_{2}\left(v_{2}\right)}\right)\right|_{v_{1}-\Delta_{\alpha}^{*}\left(v_{1}\right)}
$$

which implies, thanks to the Monotone Hazard Rate Property, that $\dot{\Delta}_{\alpha}^{*}\left(v_{1}\right)>0$ for any $\alpha<1$. 
When $v_{1} \geq p_{1}^{s m}, B$ 's outside option is $v_{1}-p_{1}^{s m}+\alpha \int_{v_{2} \geq v_{1}-p_{1}^{s m}}\left(v_{2}-v_{1}+p_{1}^{s m}\right) d G_{2}\left(v_{2}\right)$. An argument similar to the one used in the Proof of Proposition 1 in Appendix A.2 can be used to show that $I$ always prefers using a contract.

When $v_{1} \leq p_{1}^{s m}, B$ 's outside option is $\int v_{2} d G_{2}\left(v_{2}\right)$. I's profit if he offers a contract is then equal to $v_{1}+\alpha \int_{v_{2} \geq v_{1}-\Delta_{\alpha}^{*}\left(v_{1}\right)}\left(v_{2}-v_{1}+\Delta_{\alpha}^{*}\left(v_{1}\right)\right) d G_{2}\left(v_{2}\right)-\alpha \int v_{2} d G_{2}\left(v_{2}\right)-\Delta_{\alpha}^{*}\left(v_{1}\right)\left(1-G_{2}\left(v_{1}-\right.\right.$ $\left.\left.\Delta_{\alpha}^{*}\left(v_{1}\right)\right)\right)$. The derivative of this expression w.r.t. $\alpha$ is $\int_{v_{2} \geq v_{1}-\Delta_{\alpha}^{*}\left(v_{1}\right)}\left(v_{2}-v_{1}+\Delta_{\alpha}^{*}\left(v_{1}\right)\right) d G_{2}\left(v_{2}\right)-$ $\int v_{2} d G_{2}\left(v_{2}\right)$, which is negative. Since we have shown in Appendix A.2 that $I$ prefers offering a contract when $v_{1} \leq p_{1}^{s m}$ and $\alpha=1$, this also holds true when $v_{1} \leq p_{1}^{s m}$ and $\alpha<1$.

\section{A.7. Proof of Proposition 4}

$B$ 's expected gain if she reveals truthfully her valuation is now given by

$$
U_{B}\left(v_{1}\right)=v_{1}-p_{1}\left(v_{1}\right)+\alpha \int_{v_{2} \geq v_{1}-\Delta\left(v_{1}\right)}\left(v_{2}-v_{1}+\Delta\left(v_{1}\right)\right) d G_{2}\left(v_{2}\right) .
$$

Applying the same methodology as in Section A.3, the first- and second-order conditions for incentive compatibility are now given by

$$
\dot{U}_{B}\left(v_{1}\right)=1-\alpha\left(1-G_{2}\left(v_{1}-\Delta\left(v_{1}\right)\right)\right) \quad \text { and } \quad \dot{\Delta}\left(v_{1}\right) \leq 0 .
$$

For $v_{1} \geq p_{1}^{s m}$, we have $\dot{U}_{B}^{s m}\left(v_{1}\right)=1-\alpha\left(1-G_{2}\left(v_{1}-p_{1}^{s m}\right)\right.$ ) (see Section A.5). Therefore, $\dot{U}_{B}\left(v_{1}\right) \geq \dot{U}_{B}^{s m}\left(v_{1}\right)$ iff $p_{1}^{s m} \geq \Delta\left(v_{1}\right)$. Let us assume, and check a posteriori, that this indeed the case.

Define now $v_{1 \alpha}^{*}$ such that for $v \geq v_{1 \alpha}^{*}, U_{B}\left(v_{1}\right) \geq U_{B}^{s m}\left(v_{1}\right)$ and for $v \leq v_{1 \alpha}^{*}, U_{B}\left(v_{1}\right) \leq U_{B}^{s m}\left(v_{1}\right)$. We can use the first-order incentive constraint to obtain

$\int_{v_{1 \alpha}^{*}}^{\bar{v}} U_{B}\left(v_{1}\right) d G_{1}\left(v_{1}\right)=\left(1-G_{1}\left(v_{1 \alpha}^{*}\right)\right) U_{B}^{s m}\left(v_{1 \alpha}^{*}\right)+\int_{v_{1 \alpha}^{*}}^{\bar{v}} \frac{1-G_{1}\left(v_{1}\right)}{g_{1}\left(v_{1}\right)}\left(1-\alpha\left(1-G_{2}\left(v_{1}-\Delta\left(v_{1}\right)\right)\right)\right) d G_{1}\left(v_{1}\right)$.

This expression can be used to rewrite I's objective as follows

$$
\begin{aligned}
& \int_{p_{1}^{s m}}^{v_{1 \alpha}^{*}} p_{1}^{s m} G_{2}\left(v_{1}-p_{1}^{s m}\right) d G_{1}\left(v_{1}\right)-\left(1-G_{1}\left(v_{1 \alpha}^{*}\right)\right) U_{B}^{s m}\left(v_{1 \alpha}^{*}\right) \\
+ & \int_{v_{1 \alpha}^{*}}^{\bar{v}}\left(v_{1}+\int_{v_{2} \geq v_{1}-\Delta\left(v_{1}\right)}\left(\alpha\left(v_{2}-v_{1}\right)-(1-\alpha) \Delta\left(v_{1}\right)\right) d G_{2}\left(v_{2}\right)-\frac{1-G_{1}\left(v_{1}\right)}{g_{1}\left(v_{1}\right)}\left(1-\alpha\left(1-G_{2}\left(v_{1}-\Delta\left(v_{1}\right)\right)\right)\right)\right) d G_{1}\left(v_{1}\right),
\end{aligned}
$$

which has to be maximized over $\Delta(\cdot)$ and $v_{1 \alpha}^{*}$, and which must satisfy, for all $v_{1}, p_{1}^{s m} \geq \Delta\left(v_{1}\right)$ (to ensure that the net rent is increasing) and the second-order conditions for incentive compatibility $\dot{\Delta}\left(v_{1}\right) \leq 0 \forall v_{1}$.

RELAXED PROBLEM. Let us determine the solution of the so called relaxed problem in which the constraint $\dot{\Delta}(\cdot) \leq 0$ is neglected. Pointwise optimization w.r.t. $\Delta\left(v_{1}\right)$ on $\left[v_{1 \alpha}^{*}, \bar{v}\right]$ leads to (5.2). It is immediate to check that the objective is quasi-concave in $\Delta\left(v_{1}\right)$. Straightforward computations then show that Condition $(H)$ stated in Proposition 4 amounts to

$$
\dot{\Delta}_{\alpha}^{s b}\left(v_{1}\right) \leq 0 \Leftrightarrow \alpha \frac{d}{d v_{1}}\left(\frac{1-G_{1}\left(v_{1}\right)}{g_{1}\left(v_{1}\right)}\right) \leq\left.(1-\alpha) \frac{d}{d v_{2}}\left(\frac{1-G_{2}\left(v_{2}\right)}{g_{2}\left(v_{2}\right)}\right)\right|_{v_{1}-\Delta_{\alpha}^{s b}\left(v_{1}\right)},
$$

which is satisfied provided that $B$ 's bargaining power $\alpha$ is large enough.

It remains to optimize over $v_{1 \alpha}^{*}$. Using the fact that $U_{B}^{s m}\left(v_{1 \alpha}^{*}\right)=v_{1 \alpha}^{*}-p_{1}^{s m}+\alpha \int_{v_{2} \geq v_{1 \alpha}^{*}-p_{1}^{s m}}\left(v_{2}-\right.$ $\left.v_{1 \alpha}^{*}+p_{1}^{s m}\right) d G_{2}\left(v_{2}\right)$ and $\dot{U}_{B}^{s m}\left(v_{1 \alpha}^{*}\right)=1-\alpha\left(1-G_{2}\left(v_{1 \alpha}^{*}-p_{1}^{s m}\right)\right)$, the first-order condition w.r.t. 
$v_{1 \alpha}^{*}$ can be rewritten as follows (we assume that the second-order condition is satisfied)

$$
\Delta_{\alpha}^{s b}\left(v_{1 \alpha}^{*}\right)\left(1-G_{2}\left(v_{1 \alpha}^{*}-\Delta_{\alpha}^{s b}\left(v_{1 \alpha}^{*}\right)\right)\right)-p_{1}^{s m}\left(1-G_{2}\left(v_{1 \alpha}^{*}-p_{1}^{s m}\right)\right)=0 .
$$

Letting $\tilde{v}_{1 \alpha}$ be such that $\Delta_{\alpha}^{s b}\left(\tilde{v}_{1 \alpha}\right)=p_{1}^{s m}$, it is immediate to check that (A.6) holds for $v_{1 \alpha}^{*}=\tilde{v}_{1 \alpha}$.

Observe now that for $v_{1} \geq \tilde{v}_{1 \alpha}, \Delta_{\alpha}^{s b}\left(v_{1}\right) \leq \Delta_{\alpha}^{s b}\left(\tilde{v}_{1 \alpha}\right)\left(\right.$ since $\left.\dot{\Delta}_{\alpha}^{s b}(\cdot) \leq 0\right)$, so that $p_{1}^{s m} \geq \Delta_{\alpha}^{s b}\left(v_{1}\right)$ on the relevant interval.

Last, there exists a spot market zone iff $\tilde{v}_{1 \alpha} \geq p_{1}^{s m}$; otherwise all buyers with valuations $v_{1} \geq p_{1}^{s m}$ accept $I$ 's contract. Moreover, it comes immediately that $\Delta_{\alpha}^{s b}(\bar{v})=0$. Therefore, if $\dot{\Delta}_{\alpha}^{s b}\left(v_{1}\right) \leq 0 \forall v_{1}$, then $\Delta_{\alpha}^{s b}\left(v_{1}\right) \geq 0 \forall v_{1}$.

Full Bunching. Suppose now that Condition $(H)$ is never satisfied, or, equivalently, that the solution of the relaxed problem $\Delta_{\alpha}^{s b}(\cdot)$ violates the second-order incentive constraint for all possible values of $v_{1}$. The solution involves then a constant rebate $\Delta_{\alpha}^{s b}$ for all valuations $v_{1} \geq \tilde{v}_{1 \alpha}$, where the threshold $\tilde{v}_{1 \alpha}$ has to be determined endogenously.

Maximizing the same objective as in the case of the relaxed problem but with a fixed rebate, the first-order condition associated to $\Delta_{\alpha}^{s b}$ can now be written as follows

$$
\Delta_{\alpha}^{s b}=\frac{\int_{\tilde{v}_{1 \alpha}}^{\bar{v}}\left(\alpha\left(1-G_{1}\left(v_{1}\right)\right) g_{2}\left(v_{1}-\Delta_{\alpha}^{s b}\right)-(1-\alpha)\left(1-G_{2}\left(v_{1}-\Delta_{\alpha}^{s b}\right)\right) g_{1}\left(v_{1}\right)\right) d v_{1}}{\int_{\tilde{v}_{1 \alpha}}^{\bar{v}} g_{1}\left(v_{1}\right) g_{2}\left(v_{1}-\Delta_{\alpha}^{s b}\right) d v_{1}} .
$$

The first-order condition w.r.t. $\tilde{v}_{1 \alpha}$ leads to (after some manipulations) the following characterization (assuming that the second-order condition is satisfied)

$$
\int_{\tilde{v}_{1 \alpha}-p_{1}^{s m}}^{\tilde{v}_{1 \alpha}-\Delta_{\alpha}^{s b}}\left(\alpha \frac{1-G_{1}\left(\tilde{v}_{1 \alpha}\right)}{g_{1}\left(\tilde{v}_{1 \alpha}\right)}-(1-\alpha) \frac{1-G_{2}\left(v_{2}\right)}{g_{2}\left(v_{2}\right)}+\left(v_{2}-\tilde{v}_{1 \alpha}\right)\right) d G_{2}\left(v_{2}\right)=0 .
$$

$\Delta_{\alpha}^{s b}$ and $\tilde{v}_{1 \alpha}$ are jointly determined by (A.7) and (A.8). Putting $\alpha=0$ in (A.7) leads to (5.3). 